Universidad de Lima

Escuela de Posgrado

Maestría en Derecho Empresarial

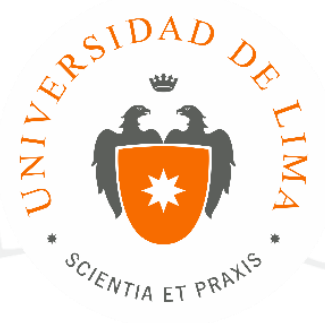

\title{
LA PROBLEMÁTICA DE LAS \\ ASOCIACIONES PÚBLICO PRIVADAS EN EL \\ PERÚ CON OCASIÓN DE LA CLÁUSULA ANTICORRUPCIÓN
}

Trabajo de investigación para optar el Grado Académico de Maestro en Derecho Empresarial

\section{Mariana Cisneros Méndez}

19892180

Asesor: Desirée Orsini Wisotzki

Lima - Perú

Julio de 2017 
A mis padres, Eduardo y Norma, ejemplo de perseverancia, ética y rectitud. 


\section{PROBLEMÁTICA DE LAS ASOCIACIONES PÚBLICO PRIVADAS (APP) EN EL PERÚ CON OCASIÓN DE LA CLÁUSULA ANTICORRUPCIÓN}




\section{TABLA DE CONTENIDO}

INTRODUCCIÓN .......................................................................................................1

\section{CAPÍTULO I: EL ESQUEMA ANTICORRUPCIÓN A NIVEL}

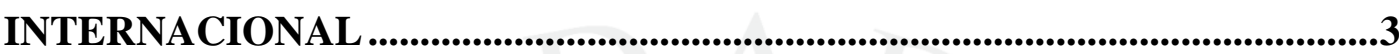

1.1 Anticorrupción en los Organismos Internacionales.............................3

1.2 Publicación de Transparencia Internacional - TI ...............................4

1.3 Banco Interamericano de Desarrollo (BID) y su Política de lucha contra la

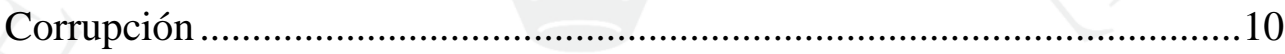

1.4 Banco Mundial y su Política de lucha contra la Corrupción ...................11

CAPÍTULO II: NORMATIVIDAD CONTRA LA CORRUPCIÓN EN EL PERÚ, PROBLEMÁTICA DE LAS APPS Y CLÁUSULA ANTICORRUPCIÓN: ANÁLISIS Y EFECTOS DE SU APLICACIÓN.....................................................14

2.1. Normativa Contra la Corrupción en el Perú ..........................................14

2.1.1 Contexto Actual de la APP en el Perú ...............................................17

2.2 Problemática de la APP en el Perú ......................................................22

2.2.1 ¿Es la APP un sistema eficiente en el Perú?....................................22

2.2.2 ¿Renégociar los contratos y suscribir adendas, abre la puerta a la corrupción? ¿Limitando esta posibilidad como lo ha recogido la reciente modificación del reglamento de APP, será una herramienta efectiva que reducirá la corrupción?

2.2.3 En qué casos el Estado debe apostar por una APP y no por el sistema de obras públicas. ¿Cuál es el criterio determinante para tomar tal decisión?..26

2.3 Cláusula anticorrupción en el reglamento de la Ley de APP: Análisis y efectos

2.3.1 Contenido mínimo de la cláusula anticorrupción en los contratos de Inversión 
2.3.2 Efectos de la aplicación de la cláusula Anticorrupción .30

2.3.3 ¿Es la cláusula anticorrupción un arma letal o de doble filo?..........31

2.3.4 Resolución de los contratos como alternativa .32

2.3.6 ¿Qué otras características deberían contemplar una cláusula anticorrupción efectiva?

CAPÍTULO III: PROPUESTA DE ESTANDARIZACIÓN DE LA CLÁUSULA ANTICORRUPCIÓN EN LA INVERSIÓN PRIVADA, PARTICULARMENTE EN LA APP. .37

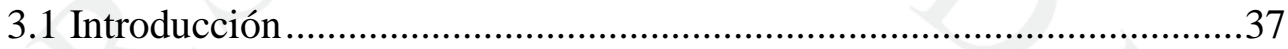

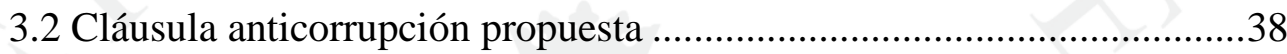

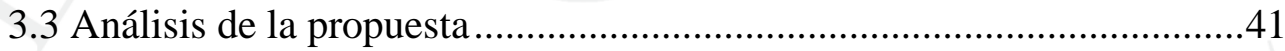

CONCLUSIONES ...................................................................................................................46

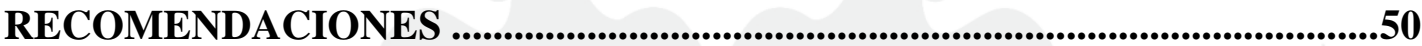




\section{ÍNDICE DE TABLAS}

Tabla 1.1 Índice de percepción de la corrupción 2016 de Transparency International............................................................ 5

Tabla 1.2 Índice de percepción de la corrupción del Perú en los últimos $19 \quad 9$ años

Tabla 2.1 Niveles de Competitividad en América Latina...................... 18

Tabla 2.2 Ranking de Competitividad Internacional 2016................... 19

Tabla 2.3 Posición de Competitividad del Perú en relación con los Países Latinoamericanos y Del Caribe 2015-2016 


\section{ÍNDICE DE ANEXO}

Anexo 1- Entrevistas a especialistas peruanos de APP........................ 


\section{INTRODUCCIÓN}

El sistema de asociación público privada (APP) en el Perú, se constituye como una modalidad de participación de inversión de la empresa privada en la que se incorpora, experiencia, conocimientos, equipos y tecnología y se distribuyen riesgos y recursos, preferentemente asumido por los privados para generar inversión en infraestructura pública o proveer de servicios públicos. (Ministerio de Economía y Finanzas del Perú MEF, 2017).

Paralelamente, la cláusula anticorrupción en el Perú, busca activarse ante el descubrimiento y/o aceptación de algún acto de corrupción en el concurso que dio origen al contrato y/o durante la ejecución del contrato, el mismo que debería y/o podría ser anulado por el Estado.

Al celebrase los contratos de inversión en la modalidad de APP, que es la tendencia actual de modalidad por parte del Gobierno peruano, la legislación nacional no disponía (hasta el 28 de marzo del 2017), de una cláusula anticorrupción. Nos preguntamos, ¿cuáles son los supuestos actos de corrupción que permitirán al Estado, ante las acciones o decisiones ilegales e ilícitas por parte de las empresas privadas individualmente o en forma consorciada, sean estas nacionales o extranjeras, activar la referida cláusula? ¿Cómo debería estar redactada dicha cláusula a efectos de cumplir con su función? ¿Y bajo qué criterios se evalúa el costo beneficio de activar o no esta facultad por parte del Estado? ¿Cuáles son los efectos en el Perú de activarse la cláusula anticorrupción en la etapa preparatoria del concurso o en la etapa de ejecución contractual? ¿Está preparado el sistema peruano sobre la base de una política anticorrupción, para asumir la resolución de un contrato de inversión relativo a un megaproyecto de infraestructura?

Uno de los antecedentes de la cláusula anticorrupción en el Perú se encuentra en los contratos de concesión de transporte de gas natural y liquido celebrados durante el año 2000, y posterior y principalmente, en el Contrato de Concesión del Gaseoducto Sur Peruano celebrado en el año 2014, (Ronceros, M., 2017). Durante el periodo 2000 
al 2016, estas cláusulas anticorrupción se siguieron utilizando voluntariamente, en el sector energético más no en otros sectores.

El tema de la anticorrupción no es un tema ajeno en el Perú, sino que a nivel internacional se enmarca en dicho contexto, es decir, hay un desarrollo relevante para combatir la corrupción por parte de los principales organismos internacionales como el Banco Mundial y el Banco Interamericano de Desarrollo. Asimismo, Transparencia Internacional, desde 1995, publica el índice de percepción de la corrupción para 176 países, entre los que se encuentra el Perú. 


\section{CAPÍTULO I: EL ESQUEMA ANTICORRUPCIÓN A NIVEL INTERNACIONAL}

Desde el año 1995, Transparencia Internacional -TI (por sus siglas en inglés) publica el Índice de Percepción de la Corrupción (IPC) creado como un indicador para medir las percepciones sobre corrupción en el sector público. El Perú forma parte de los 176 países para cuyos resultados son publicados de manera anual en el IPC.

En el presente trabajo se hará un desarrollo del último reporte emitido por TI. De otro lado, diferentes organismos internacionales que financian préstamos al Perú: Banco Mundial - BM (US\$ 2856 millones en el 2016), Banco Interamericano de Desarrollo -BID (US\$ 2,290 millones en el 2016) y Banco de Desarrollo de América Latina - CAF (US\$2,400 millones al 2014), todos ellos desarrollan políticas contra la corrupción.

Así, existe, por ejemplo, el "Marco Uniforme para Combatir y Prevenir el Fraude y la Corrupción", documento emitido en febrero de 2006 y que formula un “enfoque sistemático y armonizado para combatir la corrupción” y que, en setiembre de 2016, los mismos líderes que suscribieron dicho Marco", reconocieron que "la corrupción socava el crecimiento económico sostenible y constituye un obstáculo importante para la reducción de la pobreza".

\subsection{Anticorrupción en los Organismos Internacionales}

Existe un marco legal Internacional contra la Corrupción, siendo el principal instrumento normativo vinculante "La Convención de las Naciones Unidas contra la Corrupción” (CNUCC) que entró en vigencia en el año 2005 y cuenta con 167 países miembros. Asimismo, la Oficina de las Naciones Unidas contra la Droga y el Delito ha publicado el "Programa anticorrupción de ética y cumplimiento para las empresas: Guía práctica" (2013) evaluando los riesgos anticorrupción. Otro documento vigente es "El

\footnotetext{
${ }^{1}$ Conformado por los líderes del Grupo del Banco Africano de Desarrollo, Banco Asiático de Desarrollo, Banco Europeo para la Reconstrucción y el Desarrollo, Grupo del Banco Europeo de Inversiones, Grupo del Banco Interamericano de Desarrollo, Fondo Monetario Internacional y Grupo del Banco Mundial.
} 
Convenio de la Organización para la Cooperación y el Desarrollo Económicos de Lucha contra la Corrupción de Agentes Públicos Extranjeros en las Transacciones Comerciales Internacionales" (1997), también tenemos a la "Guía de Buenas Prácticas sobre Control Interno, Ética y Cumplimiento de Normas”, emitida por el Consejo de la Organización para la Cooperación y el Desarrollo Económicos (2010) que, entre sus recomendaciones, exhorta a los países, a que promuevan en las empresas, el establecimiento de guías, códigos, y programas de ética a través de controles internos eficientes para detectar a los empleados corruptos, pero en dichos instrumentos, se exige a los países, que castiguen los actos de corrupción de las empresas y que se les establezca así, responsabilidad a la persona jurídica.

\subsection{Publicación de Transparencia Internacional - TI}

Transparencia Internacional es un organismo no gubernamental (ONG) creado en 1993, con sede principal en Berlín, Alemania. Su objetivo es combatir la corrupción, es decir, promover medidas para combatir los crímenes de las empresas privadas, de organizaciones internacionales y la corrupción política internacionalmente.

TP define la corrupción como:

La corrupción es el abuso del poder confiado para el beneficio privado. Puede clasificarse como grandioso, mezquino y político, dependiendo de las cantidades de dinero perdido y del sector donde se produce.

Todos los años TP publica el Índice de Percepción de Corrupción a nivel mundial respecto de 176 Países. Este Índice indica cual es el grado de percepción de corrupción a nivel sector público, de acuerdo a la encuesta que se realiza al sector empresarial y analistas de cada país. El Rango de Puntuación va de 0 a 100, donde 0 y cerca de 0 es una percepción de "Muy Corrupto" y 100 o cerca de 100 es una percepción de “Ausencia o baja corrupción".

Respecto del Índice de Percepción de Corrupción 2016, tenemos como contraste los cinco primeros países con baja percepción de corrupción al 2016 están: Dinamarca (90 puntos), Nueva Zelanda (90 puntos), Finlandia (89 puntos), Suecia (88 puntos) y Suiza (86 puntos). Por otro lado, los cinco países con percepción de muy corruptos al 2016 están: Somalia (10 puntos), Sudan del Sur (11 puntos), Corea del Norte (12 puntos), Siria (13 puntos) y Yemen (14 puntos). 
Respecto del Índice de Percepción de la Corrupción 2016 para el Perú, se encuentra con una Puntuación de 35 en la posición 101 de los 176 países, conjuntamente con Gabón, Nigeria, Filipinas, Tailandia y Trinidad y Tobago. Perú respecto de los países de la Región Sudamericana, tiene por encima con bajo nivel de percepción de corrupción a Chile (66 puntos), Brasil (40 puntos), Colombia (37 puntos) y Argentina (36 puntos). Por debajo de Perú, con alto nivel de percepción de corrupción están: Bolivia (33 puntos), Ecuador (31 puntos), Paraguay (30 puntos) y Venezuela (17 puntos). (Ver Tabla 1.1)

Tabla 1.1 


\section{Índice de Percepción de la Corrupción 2016 de Transparency International}

La Puntuación del IPC correspondiente a un país o territorio indica el grado de corrupción en el sector público según la percepción de empresarios y analistas de pais, entre 100 (percepción de ausencia de corrupción) y 0 (percepción de muy corrupto).

\begin{tabular}{|c|c|c|c|c|c|c|c|c|}
\hline \multirow{2}{*}{$\begin{array}{l}\frac{n}{\pi} \\
\frac{0}{\pi} \\
\frac{0}{0} \\
\frac{0}{0} \\
0 \\
0\end{array}$} & \multirow{2}{*}{ 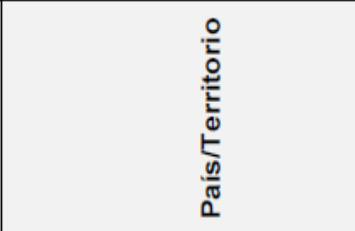 } & \multirow{2}{*}{ 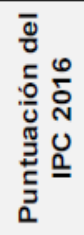 } & \multirow{2}{*}{ 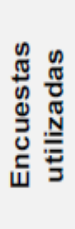 } & \multirow{2}{*}{ 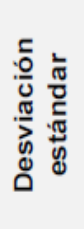 } & \multicolumn{2}{|c|}{$\begin{array}{c}\text { Intérvalo de } \\
\text { confianza del } 90 \%\end{array}$} & \multicolumn{2}{|c|}{$\begin{array}{c}\text { Rango } \\
\text { mínimo/máximo }\end{array}$} \\
\hline & & & & & $\dot{\Sigma}$ & 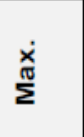 & 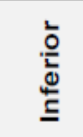 & 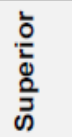 \\
\hline 1 & Dinamarca & 90 & 7 & 2,46 & 86 & 94 & 83 & 99 \\
\hline 1 & Nueva Zelanda & 90 & 7 & 2,56 & 86 & 94 & 79 & 99 \\
\hline 3 & Finlandia & 89 & 7 & 1,46 & 87 & 92 & 83 & 94 \\
\hline 4 & Suecia & 88 & 7 & 1,33 & 85 & 90 & 83 & 93 \\
\hline 5 & Suiza & 86 & 6 & 1,57 & 83 & 89 & 80 & 90 \\
\hline 6 & Noruega & 85 & 7 & 1,85 & 82 & 88 & 80 & 93 \\
\hline 7 & Singapur & 84 & 8 & 2,35 & 81 & 88 & 73 & 91 \\
\hline 8 & Países Bajos & 83 & 7 & 2,32 & 79 & 87 & 71 & 90 \\
\hline 9 & Canadá & 82 & 7 & 2,03 & 79 & 85 & 73 & 90 \\
\hline 10 & Alemania & 81 & 7 & 2,73 & 77 & 86 & 67 & 90 \\
\hline 10 & Luxemburgo & 81 & 6 & 1,96 & 78 & 84 & 72 & 85 \\
\hline 10 & Reino Unido & 81 & 7 & 2,12 & 77 & 84 & 71 & 90 \\
\hline 13 & Australia & 79 & 8 & 1,27 & 77 & 81 & 72 & 83 \\
\hline 14 & Islandia & 78 & 6 & 3,81 & 71 & 84 & 61 & 85 \\
\hline 15 & Bélgica & 77 & 7 & 1,55 & 74 & 79 & 72 & 83 \\
\hline 15 & Hong Kong & 77 & 7 & 2,62 & 73 & 82 & 67 & 87 \\
\hline 17 & Austria & 75 & 7 & 1,36 & 73 & 77 & 71 & 80 \\
\hline 18 & Estados Unidos de América & 74 & 9 & 3,15 & 69 & 80 & 64 & 90 \\
\hline 19 & Irlanda & 73 & 6 & 4,31 & 66 & 80 & 54 & 83 \\
\hline 20 & Japón & 72 & 8 & 3,02 & 67 & 77 & 52 & 78 \\
\hline 21 & Uruguay & 71 & 6 & 2,68 & 66 & 75 & 59 & 77 \\
\hline 22 & Estonia & 70 & 10 & 2,16 & 66 & 73 & 54 & 80 \\
\hline 23 & Francia & 69 & 7 & 2,97 & 64 & 74 & 52 & 76 \\
\hline 24 & Bahamas & 66 & 3 & 5,2 & 57 & 74 & 59 & 76 \\
\hline 24 & Chile & 66 & 8 & 2,65 & 61 & 70 & 54 & 76 \\
\hline 24 & Emiratos Árabes Unidos & 66 & 7 & 5,7 & 56 & 75 & 47 & 86 \\
\hline 27 & Bután & 65 & 5 & 2,12 & 62 & 69 & 59 & 71 \\
\hline 28 & Israel & 64 & 6 & 2,27 & 60 & 68 & 58 & 72 \\
\hline 29 & Polonia & 62 & 10 & 1,77 & 59 & 65 & 54 & 71 \\
\hline 29 & Portugal & 62 & 8 & 2,58 & 58 & 66 & 51 & 71 \\
\hline 31 & Barbados & 61 & 3 & 6,91 & 50 & 73 & 48 & 71 \\
\hline 31 & Katar & 61 & 7 & 7,02 & 49 & 72 & 39 & 82 \\
\hline 31 & Eslovenia & 61 & 10 & 2,44 & 57 & 65 & 46 & 71 \\
\hline 31 & Taiwán & 61 & 8 & 3,79 & 55 & 67 & 50 & 77 \\
\hline 35 & Botswana & 60 & 6 & 3,1 & 55 & 66 & 52 & 72 \\
\hline 35 & Santa Lucía & 60 & 3 & 6,8 & 49 & 71 & 47 & 69 \\
\hline 35 & San Vicente y las Granadinas & 60 & 3 & 1,66 & 57 & 63 & 58 & 63 \\
\hline 38 & Cabo Verde & 59 & 3 & 5,72 & 50 & 68 & 49 & 69 \\
\hline 38 & Dominica & 59 & 3 & 0,85 & 58 & 60 & 58 & 61 \\
\hline 38 & Lituania & 59 & 9 & 1,36 & 57 & 61 & 53 & 65 \\
\hline 41 & Brunei & 58 & 3 & 8,85 & 43 & 72 & 41 & 71 \\
\hline 41 & Costa Rica & 58 & 7 & 3,17 & 53 & 63 & 46 & 69 \\
\hline 41 & España & 58 & 7 & 4,09 & 51 & 65 & 38 & 72 \\
\hline 44 & Georgia & 57 & 6 & 3,61 & 51 & 63 & 47 & 68 \\
\hline 44 & Letonia & 57 & 9 & 2,96 & 52 & 62 & 45 & 71 \\
\hline 46 & Granada & 56 & 3 & 4,63 & 48 & 63 & 47 & 62 \\
\hline 47 & Chipre & 55 & 5 & 5,94 & 46 & 65 & 42 & 72 \\
\hline 47 & República Checa & 55 & 9 & 2,24 & 51 & 59 & 46 & 65 \\
\hline
\end{tabular}




\begin{tabular}{|c|c|c|c|c|c|c|c|c|}
\hline 47 & Malta & 55 & 5 & 1,39 & 53 & 58 & 52 & 59 \\
\hline 50 & Mauricio & 54 & 4 & 2,14 & 50 & 57 & 49 & 59 \\
\hline 50 & Ruanda & 54 & 6 & 5,07 & 46 & 62 & 40 & 76 \\
\hline 52 & Corea del Sur & 53 & 9 & 2,33 & 49 & 57 & 47 & 69 \\
\hline 53 & Namibia & 52 & 5 & 2,03 & 49 & 55 & 49 & 59 \\
\hline 54 & Eslovaquia & 51 & 8 & 3,09 & 46 & 57 & 34 & 61 \\
\hline 55 & Croacia & 49 & 9 & 2,39 & 45 & 53 & 38 & 61 \\
\hline 55 & Malasia & 49 & 8 & 2,46 & 45 & 53 & 41 & 59 \\
\hline 57 & Hungría & 48 & 9 & 2,89 & 43 & 53 & 33 & 59 \\
\hline 57 & Jordán & 48 & 8 & 3,03 & 43 & 53 & 34 & 60 \\
\hline 57 & Rumania & 48 & 10 & 3 & 43 & 53 & 37 & 61 \\
\hline 60 & Cuba & 47 & 5 & 2,9 & 42 & 52 & 40 & 54 \\
\hline 60 & Italia & 47 & 7 & 3,34 & 42 & 53 & 37 & 59 \\
\hline 62 & Santo Tomé y Príncipe & 46 & 3 & 0,93 & 44 & 47 & 44 & 47 \\
\hline 62 & Arabia Saudita & 46 & 5 & 7,54 & 33 & 58 & 22 & 66 \\
\hline 64 & Montenegro & 45 & 4 & 2,89 & 41 & 50 & 39 & 53 \\
\hline 64 & Omán & 45 & 5 & 7,07 & 33 & 56 & 24 & 67 \\
\hline 64 & Senegal & 45 & 8 & 2,63 & 40 & 49 & 32 & 54 \\
\hline 64 & Sudáfrica & 45 & 7 & 2,55 & 41 & 49 & 33 & 54 \\
\hline 64 & Suriname & 45 & 4 & 7,53 & 32 & 57 & 32 & 65 \\
\hline 69 & Grecia & 44 & 7 & 2,5 & 40 & 48 & 37 & 53 \\
\hline 70 & Bahrein & 43 & 5 & 5,96 & 33 & 53 & 34 & 66 \\
\hline 70 & Ghana & 43 & 9 & 2,89 & 39 & 48 & 30 & 54 \\
\hline 72 & Burkina Faso & 42 & 7 & 2,47 & 38 & 46 & 32 & 49 \\
\hline 72 & Serbia & 42 & 7 & 3,69 & 36 & 48 & 32 & 57 \\
\hline 72 & Islas Salomón & 42 & 3 & 3,34 & 36 & 47 & 35 & 47 \\
\hline 75 & Bulgaria & 41 & 9 & 2,2 & 38 & 45 & 34 & 53 \\
\hline 75 & Kuwait & 41 & 5 & 2,67 & 37 & 45 & 34 & 50 \\
\hline 75 & Túnez & 41 & 7 & 3,9 & 35 & 47 & 28 & 61 \\
\hline 75 & Turquía & 41 & 9 & 1,8 & 38 & 44 & 33 & 49 \\
\hline 79 & Bielorrusia & 40 & 7 & 3,93 & 33 & 46 & 28 & 56 \\
\hline 79 & Brasil & 40 & 8 & 4,34 & 33 & 47 & 25 & 61 \\
\hline 79 & China & 40 & 8 & 2,39 & 37 & 44 & 32 & 53 \\
\hline 79 & India & 40 & 8 & 2,47 & 36 & 44 & 34 & 54 \\
\hline 83 & Albania & 39 & 7 & 1,99 & 36 & 42 & 30 & 47 \\
\hline 83 & Bosnia y Herzegovina & 39 & 7 & 1,7 & 37 & 42 & 34 & 47 \\
\hline 83 & Jamaica & 39 & 6 & 1,84 & 36 & 42 & 34 & 47 \\
\hline 83 & Lesoto & 39 & 5 & 6,15 & 29 & 49 & 20 & 59 \\
\hline 87 & Mongolia & 38 & 9 & 1,7 & 35 & 41 & 32 & 47 \\
\hline 87 & Panamá & 38 & 6 & 2,29 & 34 & 42 & 32 & 47 \\
\hline 87 & Zambia & 38 & 9 & 2,91 & 34 & 43 & 28 & 59 \\
\hline 90 & Colombia & 37 & 8 & 2,27 & 34 & 41 & 28 & 47 \\
\hline 90 & Indonesia & 37 & 8 & 2,39 & 33 & 41 & 26 & 50 \\
\hline 90 & Liberia & 37 & 7 & 3,43 & 31 & 43 & 19 & 45 \\
\hline 90 & Marruecos & 37 & 7 & 1,74 & 34 & 40 & 28 & 42 \\
\hline 90 & Macedonia & 37 & 7 & 4,97 & 29 & 45 & 19 & 54 \\
\hline 95 & Argentina & 36 & 8 & 1,76 & 33 & 39 & 29 & 46 \\
\hline 95 & Benin & 36 & 6 & 3,8 & 29 & 42 & 20 & 47 \\
\hline 95 & El Salvador & 36 & 7 & 2,76 & 31 & 40 & 22 & 45 \\
\hline 95 & Kosovo & 36 & 5 & 3,17 & 31 & 41 & 27 & 47 \\
\hline 95 & Maldivas & 36 & 3 & 5,66 & 27 & 46 & 27 & 47 \\
\hline 95 & Sri Lanka & 36 & 7 & 1,64 & 34 & 39 & 28 & 41 \\
\hline 101 & Gabón & 35 & 4 & 0,97 & 33 & 36 & 32 & 37 \\
\hline 101 & Níger & 35 & 5 & 3,25 & 29 & 40 & 24 & 44 \\
\hline 101 & Perú & 35 & 7 & 2,04 & 32 & 39 & 29 & 45 \\
\hline 101 & Filipinas & 35 & 9 & 1,58 & 33 & 38 & 29 & 43 \\
\hline 101 & Tailandia & 35 & 9 & 2,44 & 31 & 39 & 22 & 44 \\
\hline 101 & Timor Oriental & 35 & 3 & 5,97 & 25 & 44 & 24 & 45 \\
\hline 101 & Trinidad y Tobago & 35 & 5 & 2,48 & 31 & 39 & 29 & 43 \\
\hline 108 & Argelia & 34 & 6 & 2,94 & 29 & 39 & 22 & 44 \\
\hline 108 & Côte d'Ivoire & 34 & 8 & 2,03 & 31 & 38 & 28 & 47 \\
\hline 108 & Egipto & 34 & 6 & 2,72 & 29 & 38 & 22 & 42 \\
\hline 108 & Etiopía & 34 & 9 & 1,37 & 31 & 36 & 24 & 38 \\
\hline 108 & Guayana & 34 & 6 & 3,57 & 29 & 40 & 25 & 47 \\
\hline
\end{tabular}




\begin{tabular}{|c|c|c|c|c|c|c|c|c|}
\hline 113 & Armenia & 33 & 6 & 4,01 & 26 & 40 & 17 & 45 \\
\hline 113 & Bolivia & 33 & 8 & 2,85 & 28 & 37 & 18 & 44 \\
\hline 113 & Vietnam & 33 & 8 & 2,46 & 29 & 38 & 19 & 41 \\
\hline 116 & Mali & 32 & 6 & 1,75 & 29 & 35 & 24 & 35 \\
\hline 116 & Pakistán & 32 & 7 & 2,12 & 28 & 35 & 20 & 37 \\
\hline 116 & Tanzania & 32 & 9 & 1,84 & 29 & 35 & 22 & 38 \\
\hline 116 & Togo & 32 & 5 & 4,21 & 25 & 39 & 23 & 47 \\
\hline 120 & República Dominicana & 31 & 6 & 1,89 & 28 & 34 & 24 & 37 \\
\hline 120 & Ecuador & 31 & 6 & 1,96 & 28 & 35 & 22 & 37 \\
\hline 120 & Malawi & 31 & 9 & 2,11 & 28 & 35 & 19 & 38 \\
\hline 123 & Azerbaiyán & 30 & 7 & 5,13 & 22 & 39 & 9 & 47 \\
\hline 123 & Djibouti & 30 & 3 & 8,23 & 17 & 44 & 20 & 47 \\
\hline 123 & Honduras & 30 & 7 & 3,05 & 25 & 35 & 19 & 41 \\
\hline 123 & Laos & 30 & 4 & 6,19 & 20 & 40 & 16 & 45 \\
\hline 123 & Méjico & 30 & 8 & 1,56 & 28 & 33 & 24 & 37 \\
\hline 123 & Moldavia & 30 & 9 & 2,18 & 27 & 34 & 23 & 40 \\
\hline 123 & Paraguay & 30 & 6 & 2,68 & 25 & 34 & 22 & 37 \\
\hline 123 & Sierra Leona & 30 & 8 & 2,94 & 25 & 35 & 19 & 40 \\
\hline 131 & Irán & 29 & 7 & 2,47 & 25 & 33 & 19 & 35 \\
\hline 131 & Kazajstán & 29 & 9 & 3,35 & 23 & 34 & 16 & 45 \\
\hline 131 & Nepal & 29 & 6 & 2,33 & 25 & 33 & 21 & 35 \\
\hline 131 & Rusia & 29 & 9 & 2,73 & 24 & 33 & 18 & 41 \\
\hline 131 & Ucrania & 29 & 9 & 1,97 & 25 & 32 & 19 & 36 \\
\hline 136 & Guatemala & 28 & 6 & 2,58 & 24 & 32 & 19 & 35 \\
\hline 136 & Kirguistán & 28 & 7 & 2,08 & 24 & 31 & 21 & 35 \\
\hline 136 & Líbano & 28 & 7 & 2,5 & 24 & 32 & 20 & 37 \\
\hline 136 & Myanmar & 28 & 8 & 3,69 & 22 & 34 & 19 & 50 \\
\hline 136 & Nigeria & 28 & 9 & 1,98 & 24 & 31 & 20 & 37 \\
\hline 136 & Papúa Nueva Guinea & 28 & 5 & 3,01 & 23 & 32 & 19 & 35 \\
\hline 142 & Guinea & 27 & 5 & 2,54 & 22 & 31 & 22 & 36 \\
\hline 142 & Mauritania & 27 & 5 & 3,62 & 21 & 33 & 15 & 35 \\
\hline 142 & Mozambique & 27 & 8 & 2,57 & 23 & 31 & 14 & 37 \\
\hline 145 & Bangladesh & 26 & 7 & 4,13 & 19 & 33 & 17 & 50 \\
\hline 145 & Camerún & 26 & 9 & 3,04 & 21 & 31 & 11 & 41 \\
\hline 145 & Gambia & 26 & 5 & 7,2 & 14 & 38 & 5 & 44 \\
\hline 145 & Kenia & 26 & 9 & 1,72 & 24 & 29 & 19 & 35 \\
\hline 145 & Madagascar & 26 & 7 & 2,88 & 21 & 30 & 14 & 34 \\
\hline 145 & Nicaragua & 26 & 7 & 1,98 & 23 & 29 & 19 & 35 \\
\hline 151 & Tayikistán & 25 & 6 & 5,26 & 16 & 34 & 11 & 48 \\
\hline 151 & Uganda & 25 & 9 & 2,24 & 22 & 29 & 13 & 37 \\
\hline 153 & Comoras & 24 & 3 & 12,81 & 3 & 45 & 2 & 47 \\
\hline 154 & Turkmenistán & 22 & 4 & 1,32 & 20 & 24 & 19 & 25 \\
\hline 154 & Zimbabue & 22 & 9 & 2,59 & 18 & 26 & 13 & 37 \\
\hline 156 & Camboya & 21 & 8 & 2,82 & 16 & 26 & 13 & 37 \\
\hline 156 & República Democrática del Congo & 21 & 7 & 2,13 & 18 & 25 & 13 & 32 \\
\hline 156 & Uzbekistán & 21 & 7 & 2,35 & 17 & 25 & 13 & 32 \\
\hline 159 & Burundi & 20 & 6 & 1,53 & 18 & 23 & 13 & 24 \\
\hline 159 & República Centroafricana & 20 & 4 & 4,04 & 13 & 27 & 10 & 28 \\
\hline 159 & Chad & 20 & 5 & 2,67 & 16 & 24 & 10 & 24 \\
\hline 159 & Haití & 20 & 5 & 1,81 & 17 & 23 & 15 & 24 \\
\hline 159 & República del Congo & 20 & 5 & 1,78 & 17 & 23 & 13 & 24 \\
\hline 164 & Angola & 18 & 4 & 1,68 & 15 & 21 & 15 & 22 \\
\hline 164 & Eritrea & 18 & 5 & 6,24 & 8 & 28 & 0 & 34 \\
\hline 166 & Irak & 17 & 5 & 1,87 & 14 & 20 & 10 & 20 \\
\hline 166 & Venezuela & 17 & 7 & 1,41 & 15 & 20 & 13 & 22 \\
\hline 168 & Guinea-Bissau & 16 & 4 & 2,09 & 13 & 20 & 13 & 22 \\
\hline 169 & Afganistán & 15 & 5 & 1,74 & 12 & 17 & 10 & 20 \\
\hline 170 & Libia & 14 & 4 & 2 & 11 & 17 & 10 & 19 \\
\hline 170 & Sudán & 14 & 7 & 2,99 & 9 & 19 & 2 & 22 \\
\hline 170 & Yemen & 14 & 7 & 3,05 & 9 & 19 & 2 & 28 \\
\hline 173 & Siria & 13 & 5 & 1,97 & 10 & 16 & 8 & 19 \\
\hline 174 & Corea del Norte & 12 & 3 & 1,39 & 10 & 15 & 10 & 15 \\
\hline 175 & Sudán del Sur & 11 & 5 & 3,21 & 5 & 16 & 2 & 19 \\
\hline 176 & Somalia & 10 & 5 & 2,98 & 5 & 15 & 0 & 17 \\
\hline
\end{tabular}

Fuente: Índice de Percepción de la Corrupción 2016 de Transparency International.s.f.. Recuperado de http://transparencia.org.es/wp-content/uploads/2017/01/tabla_sintetica_ipc-2016.pdf 
En relación a los últimos 19 años que se registra al Perú desde el 1998 en el IPC (Expansión / datos macro.com), empezó con 45 puntos, bajando sistemáticamente, constituyéndose los años de mayor percepción de corrupción el 2004 y 2008 llegando a 30 puntos. Lamentablemente, la tendencia para el Perú, entendemos que seguirá hacia la baja, con mayores niveles de percepción de corrupción, a raíz de las recientes declaraciones de la empresa Odebrecht a finales del 2016 y durante el 2017, que incluye el inicio de procesos investigatorios a varios ex Presidentes de la República, con lo cual se estima una paralización de nuevas inversiones. (Ver Tabla 1.2)

Tabla 1.2

Perú - Índice de Percepción de la Corrupción

\begin{tabular}{|c|c|c|}
\hline FECHA & $\begin{array}{l}\text { Ranking de la } \\
\text { Corrupción }\end{array}$ & Índice la Corrupción \\
\hline 2016 & 101 & 35 \\
\hline 2015 & 88 & 36 \\
\hline 2014 & 85 & 38 \\
\hline 2013 & 83 & 38 \\
\hline 2012 & 83 & 38 \\
\hline 2011 & 80 & 34 \\
\hline 2010 & 78 & 35 \\
\hline 2009 & 75 & 37 \\
\hline 2008 & 72 & 30 \\
\hline 2007 & 72 & 35 \\
\hline 2006 & 70 & 33 \\
\hline 2005 & 65 & 35 \\
\hline 2004 & 67 & 30 \\
\hline 2003 & 59 & 37 \\
\hline 2002 & 45 & 40 \\
\hline 2001 & 44 & 41 \\
\hline 2000 & 41 & 44 \\
\hline 1999 & 40 & 45 \\
\hline 1998 & 41 & 45 \\
\hline
\end{tabular}

Fuente: Expansión/datos macro.com. s.f. Perú - Índice de Percepción de la Corrupción. Recuperado de http://www.datosmacro.com/estado/indice-percepcion-corrupcion/peru 


\subsection{Banco Interamericano de Desarrollo (BID) y su Política de lucha contra la Corrupción}

Conforme se recoge de la página web oficial del BID, esta organización tiene una política definida contra la corrupción, siendo ello así, en el año 2001, aprobó la estrategia denominada "Fortalecimiento de un Marco Sistémico contra la Corrupción para el Banco Interamericano del Desarrollo" documento de 19 páginas en idioma inglés, mediante el cual el BID actúa en la prevención de la corrupción en tres (03) frentes: 1) fortalecer la integridad del personal del Banco; 2) que los proyectos financiados por el Banco estén libres de corrupción; y, 3) prestar apoyo a los países a quienes se les presta financiamiento para fortalecer sus políticas públicas contra la corrupción.

En el desarrollo del frente 1) y 2) referidos en el párrafo precedente, el BID refiere en su página oficial, que la corrupción es una práctica prohibida y entienden que la capacidad para combatirla se debe en mayor parte a la información que puedan proporcionar los denunciantes sean internos (funcionarios o trabajadores del Banco) o externos (instituciones o personas en los países prestatarios del Banco). El BID tiene una la Oficina de Integridad Institucional (OII) que lleva a cabo la investigación contra actos de corrupción en los proyectos que financia. Existen tres formas para iniciar denuncias sea por un tercero externo o algún funcionario o servidor del Banco: i) Por correo electrónico, llenando un formulario, en especial si la denuncia es anónima; ii) Por teléfono o fax; y, iii) Personalmente o por correo certificado a la dirección del BID en New York.

El BID solicita que los denunciantes tengan en cuenta, responder en sus denuncias, a las siguientes preguntas: i) Si lo tuviera: Nombre y Número del Proyecto financiado por el BID; ii) Quién cree que incurrió en fraude y quienes otros pueden estar involucrados; iii) ¿Qué ocurrió? (describa hechos con el mayor detalle); iv) ¿Cuándo ocurrió? (fechas, horas, cuantas veces ocurrió); v) ¿Dónde ocurrió? (Ciudad, País, domicilio, número de oficina, etc.); vi) ¿Quién más puede tener información?; y, vi) ¿Quién más sabe que usted mandará esta información?

Complementariamente para desarrollar el frente 3) arriba citado, referido en el primer párrafo del numeral 1.3 del presente trabajo de investigación, el BID tiene ciertos programas mediante los cuales financia proyectos innovadores de los Gobiernos 
de los países de la Región, a fin de que fortalezcan la transparencia de la gestión pública, fortalezcan sus políticas públicas de prevención y combate contra la corrupción, fortalezcan la institucionalidad de sus organismos e instituciones públicas, entre ellas al poder legislativo en su rol fiscalizador. Este financiamiento lo realizan a través de un Fondo Fiduciario de Transparencia (FFT).

El BID aprobó en el año 2009, "El Plan de Acción para el Apoyo a los Países en sus Esfuerzos por Combatir la Corrupción y Fomentar la Transparencia” (PAACT), donde se establecieron estrategias y acciones para plantear mejores métodos y desarrollo de capacidades humanas en la lucha contra la corrupción, que va desde la fase preventiva, la fase de control o fiscalizadora y la fase sancionadora o punitiva.

Este Plan tiene (04) Áreas Priorizadas: i) Fortalecimiento del Enfoque País (previo diagnóstico del país, presentar una estrategia nacional a mediano plazo); ii) Fortalecimiento del Enfoque Sectorial (previo diagnóstico, establecer un marco institucional de un área o sector específico contra la corrupción, a través del análisis de "la cadena de valor de un producto o servicio público en un determinado sector, determinando en que etapas hay mayores riesgos de corrupción para prevenir o mitigar las posibilidades de cometerse dichos actos; iii) Fortalecimiento del marco institucional del País (se apoya para que se implementen tratados internacionales contra la corrupción, que se fortalezcan los sistemas y oficinas de control interno y externo del país y que se fortalezca a la sociedad civil en su rol fiscalizador); y, iv) Consolidación de Conocimiento y Capacidad (establecer y compartir mejores e innovadoras prácticas).

\subsection{Banco Mundial y su Política de lucha contra la Corrupción}

La Política Anticorrupción del Banco Mundial (BM) se enmarca en los Instrumentos Internacionales de la Organización de las Naciones Unidas (ONU) y de la Organización para la Cooperación y el Desarrollo Económicos (OCDE), principalmente, y, son aquellos a los que nos hemos referido en la introducción del presente capítulo. Es importante resaltar que la "Convención de las Naciones Unidades contra la corrupción" no tiene una definición de corrupción, ya que sus miembros optaron por no ceñirla a determinados actos penales, sino que teniendo una amplia gama de actos ilegales que podían quedarse fuera de una definición. Por ello, era mejor tener un consenso mínimo de ciertas manifestaciones de corrupción y que cada país ya establecería sus propias 
definiciones, sobre la base de este estándar mínimo de la Convención. En ese sentido, las principales manifestaciones de la corrupción son:

- El soborno de funcionarios públicos nacionales;

- El soborno de funcionarios públicos extranjeros y funcionarios de organizaciones públicas internacionales;

- El soborno en el sector privado;

- La malversación en el sector privado;

- El tráfico de influencias;

- El abuso de funciones;

- El enriquecimiento ilícito;

- El blanqueo del producto del delito;

- El encubrimiento del producto del delito; y,

- La obstrucción a la justicia.

Es importante resaltar que la Convención, no solo contempla la corrupción entre las empresas y su relación con el Estado, sino que también abarca la relación de corrupción entre empresas.

El BM tiene una Guía Práctica que está contenida en el "Programa anticorrupción de ética y cumplimiento para las empresas", en el cual han establecido que, para prevenir y/o combatir eficazmente la corrupción dentro de una empresa, debe inicialmente establecerse una "Evaluación de Riesgos de la Empresa". Se entiende que los riesgos de corrupción de una empresa a otra van a variar, es decir, serán diferenciados, en función de factores como el tamaño y conformación empresarial, entre otros. Inicialmente corresponde evaluar y determinar cuáles son los riesgos de corrupción legales, comerciales, operativos, entre otros y luego asignarles una prioridad y posteriormente cuantificarlos. Para esta evaluación de riesgos, es determinante que lo realice personal altamente calificado y debe involucrar a los empleados que estén más expuestos a la corrupción (por ejemplo, los de abastecimiento y el área de contratos) y todo el proceso deberá documentarse. En este análisis, consideran también relevante, el incluir en la evaluación de riesgos, un sistema de incentivos en la empresa para fomentar la honestidad. A su vez, deben establecer el conjunto de actividades para 
mitigar los riesgos, incluirse al personal directivo para que se comprometa y las empresas deberán publicar sus programas y prácticas anticorrupción para que la población tenga acceso. 


\section{CAPÍTULO II: NORMATIVIDAD CONTRA LA CORRUPCIÓN EN EL PERÚ, PROBLEMÁTICA DE LAS APPS Y CLÁUSULA ANTICORRUPCIÓN: ANÁLISIS Y EFECTOS DE SU APLICACIÓN}

\subsection{Normativa Contra la Corrupción en el Perú}

En el Perú, se viene armando un sistema integral contra la corrupción, que permita abarcar los tres niveles de gobierno, los tres Poderes del Estado, la sociedad civil y al ciudadano de a pie. En ese sentido, el Poder Ejecutivo anunció en febrero del 2017, una serie de medidas y disposiciones normativas a emitir para lograr este fin, entre ellas: i) la modificación a la Ley de Contrataciones del Estado, en el sentido que no se permitirá a las empresas sentenciadas por actos de corrupción, participar de los procesos de licitación con el Estado; ii) las empresas corruptas no podrán trasferir sus activos y/o derechos en el exterior, sin previamente pedir autorización al Estado (Ministerio Justicia) y sin haber cumplido sus obligaciones en el Perú para el pago de acreencias laborales, tributarias, comerciales (proveedores) y civiles/penales (reparación al Estado); iii) la incorporación de la Cláusula Anticorrupción en todos los contratos del Estado, en particular en las concesiones, bajo sanción de nulidad; iv) el establecimiento de la muerte civil para los funcionarios y servidores públicos corruptos por delitos contra la Administración Pública ${ }^{2}$ inhabilitándolos hasta por veinte años y perpetua en dos supuestos $^{3}$, no pudiendo volver a trabajar para el Estado, disposiciones contempladas en el Decreto Legislativo que modifica el Código Penal y el Código de Ejecución Penal a fin de establecer y ampliar el plazo de duración de la Pena de Inhabilitación Principal e incorporar la Inhabilitación Perpetua para los Delitos cometidos contra la Administración Pública, y crea el Registro Único de Condenados

\footnotetext{
${ }^{2}$ Los Delitos contra la Administración Publica contemplados en el Decreto Legislativo N. ${ }^{\circ} 1234$ son: concusión, cobro indebido, colusión simple y agravada, peculado doloso y culposo, peculado de uso, malversación, soborno internacional pasivo, cohecho activo genérico, cohecho activo transnacional, cohecho pasivo específico, tráfico de influencias y enriquecimiento ilícito.

${ }^{3}$ i) cuando el agente integre una organización criminal o actúe por orden de ella; y, ii) cuando se afecten Programas de apoyo social, de desarrollo o asistenciales, cuyo valor afectado supere las 15 UIT (S/ 60,750.00).
} 
Inhabilitado (Decretos Legislativos N. ${ }^{\circ}$ 1243, 2017); y, v) creación del sistema de recompensas para funcionarios y ciudadanos que denuncien actos de corrupción, a través del Sistema Nacional de Atención de Denuncias (SINAD) a cargo de la Contraloría General de la República, que incluye denuncias es línea a través de la página web: www.contraloria.gob.pe

Un cambio importante en la normativa, es la incorporación obligatoria de la Cláusula Anticorrupción en los contratos que suscriba el Estado bajo Ley de contrataciones del Estado (Ley N. ${ }^{\circ}$ 30225, 2014), cuya última modificación mediante Decreto Legislativo N. ${ }^{\circ} 1341$ (2017), lo recoge en su artículo 32. Igualmente, el Contratista, bajo sanción de nulidad del contrato, deberá incorporar una cláusula en la que se obliga a no participar de actos o prácticas corruptas.

Artículo 32. Contrato

32.3 Los contratos regulados por la presente norma incluyen necesariamente y bajo responsabilidad las cláusulas referidas a: a) Garantías, b) Anticorrupción, c) Solución de controversias y d) Resolución de contrato por incumplimiento, conforme a lo previsto en el reglamento.

Artículo 40. Responsabilidad del Contratista

40.5 En todos los casos, los contratos incluirán una cláusula de no participación en prácticas corruptas, conforme al numeral 32.3. del artículo 32 de la presente Ley, bajo sanción de nulidad.

Complementariamente, el reglamento de la precitada Ley, recoge en su última modificación (Decreto Supremo N. ${ }^{\circ}$ 056-2017-EF, 2017), lo referente a la cláusula anticorrupción en el artículo 116, lo siguiente:

116.4. Cláusulas Anticorrupción

Conforme a lo establecido en los artículos 32 y 40 de la Ley, todos los contratos deben incorporar cláusulas anticorrupción, bajo sanción de nulidad. Dichas cláusulas deben tener el siguiente contenido mínimo:

a) La declaración y garantía del contratista de no haber, directa o indirectamente, o tratándose de una persona jurídica a través de sus socios, integrantes de los órganos de 
administración, apoderados, representantes legales, funcionarios, asesores o personas vinculadas a las que se refiere el artículo 248-A, ofrecido, negociado o efectuado, cualquier pago o, en general, cualquier beneficio o incentivo ilegal en relación al contrato.

b) La obligación del contratista de conducirse en todo momento, durante la ejecución del contrato, con honestidad, probidad, veracidad e integridad y de no cometer actos ilegales o de corrupción, directa o indirectamente o a través de sus socios, accionistas, participacionistas, integrantes de los órganos de administración, apoderados, representantes legales, funcionarios, asesores y personas vinculadas a las que se refiere el artículo 248-A.

c) El compromiso del contratista de: (i) comunicar a las autoridades competentes, de manera directa y oportuna, cualquier acto o conducta ilícita o corrupta de la que tuviera conocimiento; y (ii) adoptar medidas técnicas, organizativas y/o de personal apropiadas para evitar los referidos actos o prácticas.

El incumplimiento de las obligaciones establecidas en estas cláusulas, durante la ejecución contractual, da el derecho a la Entidad correspondiente a resolver automáticamente y de pleno derecho el contrato, bastando para tal efecto que la Entidad remita una comunicación informando que se ha producido dicha resolución, sin perjuicio de las acciones civiles, penales y administrativas a que hubiera lugar.

A su vez, el reglamento establece los casos en los que las personas jurídicas o las personas naturales que la conforman o que estén vinculadas empresarialmente, se encuentran impedidas de participar como postores y/o contratistas en los procesos de licitaciones y concursos que convoque el Estado:

\section{8-A. Impedimento por Prácticas Corruptas}

248-A.1. El impedimento previsto en el literal n) del numeral 11.1 del artículo 11 de la Ley se aplica a:

a) Las personas jurídicas, cuyos representantes legales o personas vinculadas han sido condenados en el país o en el extranjero, mediante sentencia consentida o ejecutoriada, por delitos de concusión, peculado, corrupción de funcionarios, enriquecimiento ilícito, tráfico de influencias, delitos cometidos en remates o procedimientos de selección o delitos equivalentes en otros países.

b) Las personas jurídicas o sus vinculadas que, directamente o a través de sus representantes legales, hubiesen admitido o reconocido la comisión de cualquiera de los 
delitos señalados en el literal precedente, ante alguna autoridad nacional o extranjera competente.

c) Los consorciados cuyos representantes legales o personas vinculadas han sido condenados en el país o en el extranjero, mediante sentencia consentida o ejecutoriada, por los delitos previstos en el literal a) del presente artículo, o han admitido o reconocido la comisión de cualquiera de dichos delitos, ante alguna autoridad nacional o extranjera competente.

En el anexo de definiciones, se contempla la definición de Acto de corrupción:

Acto de corrupción: Es el requerimiento o aceptación por, o el ofrecimiento u otorgamiento a, ya sea directa o indirectamente, un servidor público o persona que ejerce funciones públicas, de cualquier objeto de valor pecuniario u otros beneficios como dádivas, favores, promesas o ventajas para sí mismo o para otra persona o entidad a cambio de la realización u omisión de cualquier acto en el ejercicio de sus funciones públicas.

Por otro lado, el Poder Ejecutivo promulgó el Decreto de Urgencia que asegura la continuidad de Proyectos de Inversión para la prestación de Servicios Públicos y cautela el pago de la reparación civil a favor del Estado en casos de corrupción (Decreto de Urgencia N. ${ }^{\circ}$ 003-2017, 2017). Esta norma busca que ante actos de corrupción cometidas por empresas, sus socios, representantes o consorcios sentenciados por actos de corrupción o que declaren haber realizado dichos actos, sea en el Perú o en el extranjero, no se paralicen las obras bajo los contratos de las normas de contrataciones del Estado (empresas contratistas corruptas) y de las APP (empresas concesionarias corruptas) y así, se prosiga con la cadena de pagos comerciales, laborales, tributarios, entre otros, porque la empresa corrupta no podrá transferir al exterior sus capitales, acciones o derechos, pues quedaran suspendidos hasta que page la reparación civil al Estado o hasta que venza la norma (13 de febrero de 2018).

Lamentablemente, es un Decreto de Urgencia, cuya vigencia es temporal y ésta es particularmente de un (01) año de vigencia, debiendo haberse recogido en una norma de rango de Ley, para que su aplicación sea en forma permanente.

\subsubsection{Contexto Actual de la APP en el Perú}


Antes de referirnos en concreto a las normas que buscan impedir actos de corrupción en el marco de proyectos bajo la modalidad de APP, vamos a referirnos de manera general a la normativa que rige dicha figura.

La APP no es una figura nueva en el Perú, como lo refiere la Abogada Magali Lazo Guevara (8 de setiembre de 2016). En "Nuevas reglas de fomento de la inversión privada mediante APP"; su antecedente la encontramos ya en la Ley de Promoción de la Inversión Privada de las Empresas del Estado (Decreto Legislativo N. ${ }^{\circ} 674,1991$ ) y en las Leyes Orgánicas de Gobiernos Regionales (Ley N. ${ }^{\circ}$ 27867, 2002) y de Municipalidades (Ley N. ${ }^{\circ}$ 27972, 2003), así como la Ley Marco de Promoción de la Inversión Descentralizada (Ley N. ${ }^{\circ}$ 28059, 2003).

La primera norma que sistematiza la APP, es la Ley Marco de APP para la generación de empleo productivo (Decreto Legislativo N. ${ }^{\circ} 1012$, 2008), la cual fue reemplazada por el Decreto Legislativo N. ${ }^{\circ} 1224$, (2015), modificada por el Decreto Legislativo N. ${ }^{\circ} 1251$ (2016).

Es importante observar como el Perú a través de su legislación de avanzada en APP, fue ganando terreno como país con buen clima para la atracción de las inversiones, en particular, las inversiones en infraestructura pública y principalmente en los últimos ocho (08) años, lo que permitió posicionarse como país estable en sus niveles de competitividad y particularmente a nivel de la región latinoamericana (The Economic, Intelligence Unit, 2017) (Ver Tabla 2.1). El Word Economic Forum (WEF) o Fórum Económico Mundial publicó el 27 de setiembre del 2016, el Informe de Competitividad Global 2016-2017, donde el Perú está ubicado en el puesto 67 (Ver Tabla 2.2), tercero de los Países de Sudamérica, después de Chile y Colombia y sexto en Latinoamérica y el Caribe (Sociedad Nacional de Industrias y Centro de Desarrollo Industrial, 2015) (Ver Tabla 2.3).

Tabla 2.1

Niveles de competitividad en América Latina

Infrascope 2017 overall score

\begin{tabular}{|c|c|c|}
\hline Rank & & Score /100 \\
\hline$=1$ & Colombia & 74 \\
\hline$=1$ & Chile & 74 \\
\hline 3 & Brazil & 72 \\
\hline
\end{tabular}




\begin{tabular}{|c|c|c|}
\hline 4 & Jamaica & 71 \\
\hline 5 & Perú & 69 \\
\hline 6 & Mexico & 68 \\
\hline 7 & Honduras & 65 \\
\hline$=8$ & El Salvador & 64 \\
\hline$=8$ & Nicaragua & 64 \\
\hline$=11$ & Uruguay & 64 \\
\hline$=11$ & Costa Rica & 62 \\
\hline 13 & Guatemala & 62 \\
\hline 14 & Paraguay & 58 \\
\hline 14 & Trinidad y Tobago & 56 \\
\hline 16 & Panamá & 51 \\
\hline 17 & República & 49 \\
\hline 18 & Dominicana & 48 \\
\hline 19 & Argentina & 44 \\
\hline \multirow{2yy}{*yy}{$\begin{array}{l}\text { Emesarrollado: (60-79) } \\
\text { Naciente: (0-29) }\end{array}$} & Ecuador & 8 \\
\hline
\end{tabular}

Fuente: The Economist Intelligence Unit Limited 2017, p 7. Recuperado de http://infrascope.eiu.com/wpcontent/uploads/2017/02/EIU_IDB_INFRASCOPE_2017-FINAL-1.pdf

Tabla 2.2

Ranking de Competitividad Internacional 2016. Foro Económico Mundial (World Economic Forum - WEF) 


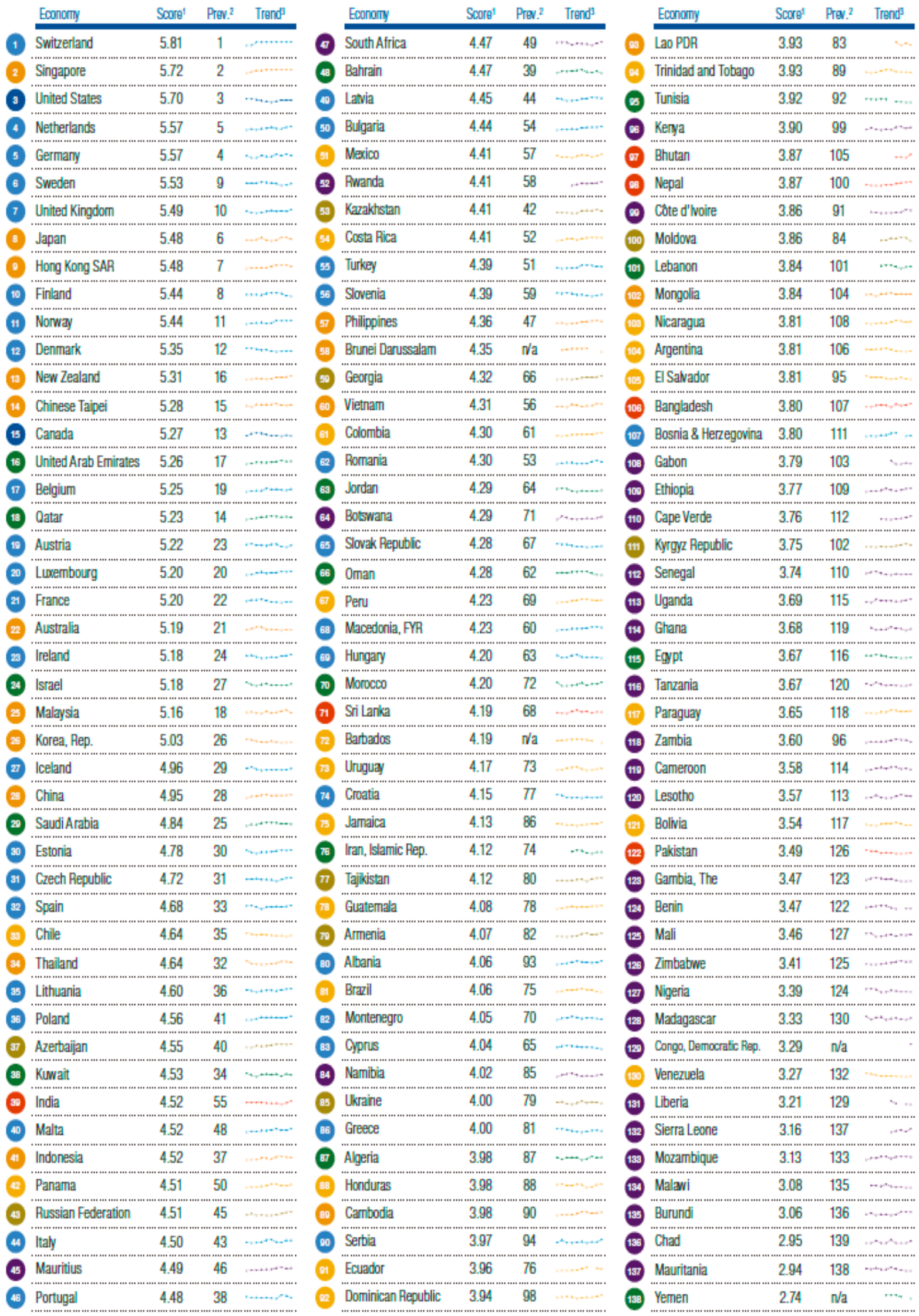

Fuente: The Global Competitiveness Report 2016-2017. p. xiii. Recuperado de http://www.cdi.org.pe/pdf/IGC/2016-2017/the_global_competitiveness_report_2016-2017.pdf 
Tabla 2.3.

Posición de competitividad del Perú en relación con los países latinoamericanos y del caribe 2015-2016

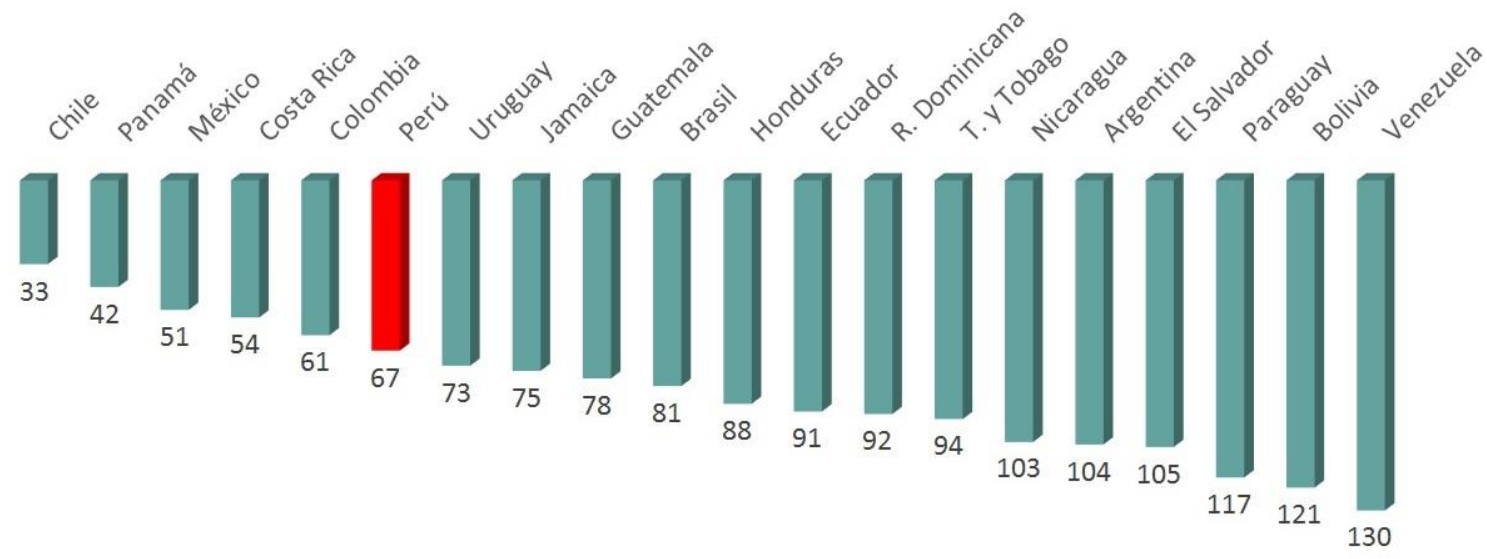

Fuente: Ranking Latinoamérica y el Caribe - IGC 2015-2016.

(25 de setiembre de 2015). CDI-SIN. Recuperado de http://www2.congreso.gob.pe/sicr/cendocbib/con4_uibd.nsf/E54FA8181F9A94B005257ED50065D64A/ \$FILE/NOTA_DE_PRENSA_IGC_2015-2016_CDI.pdf

A su vez, desde el 2012, el Perú ocupa el tercer lugar en entorno favorable para APP a nivel regional según el Infrascopio ${ }^{4}$ del BID.

Para René Cornejo Díaz, especialista peruano en APP a nivel nacional e internacional, en la entrevista realizada para el presente trabajo de investigación (entrevista personal, mayo de 2017):

La experiencia peruana a nivel institucional y normativo, es pues un referente, en prácticamente todos los países. La diferencia está más bien a nivel de capacidades institucionales que es donde en nuestro país tenemos falencias.

Asimismo, el especialista peruano en APPs, el Economista Alonso Segura Vasi, refiere en la entrevista realizada igualmente para el presente trabajo (2017), que a nivel normativo y de gestión en APP, son líderes y pioneros, Inglaterra (Infrastructure UK) y a nivel de la Región está Chile y luego en su opinión vendría Perú.

\footnotetext{
${ }^{4}$ El Infrascopio es una herramienta interactiva que mide la inversión privada en infraestructura a través de la APP en 19 países de América Latina y el Caribe. Es elaborado por Inter - American Development Bank (IDB)
} 
Pero si bien Perú ha alcanzado un importante desarrollo a nivel normativo, es un buen referente a nivel de los países de la región y ha logrado atraer la inversión privada internacional en los últimos años, también es cierto que el sistema de APP es perfectible y como todo sistema, se presentan problemas que deben ser analizados y superados con medidas razonables.

\subsection{Problemática de la APP en el Perú}

Sin embargo, llama la atención los cambios tan frecuentes en la legislación peruana y la cantidad de proyectos trabados, algunos de ellos por sonados escándalos relacionados con la reciente corrupción y la falta de nuevos proyectos de relevancia. Surge la pregunta entonces, ¿si la solución a los obstáculos antes mencionados pasa por modificar la legislación vigente o si son otras las falencias a corregir?

El especialista en APP, Alonso Segura Vasi comenta que, frente a la problemática de APP, se empezó con un diagnóstico, es decir, el estado situacional y mapeo de la problemática de los proyectos y se montó en el 2013, la unidad de seguimiento de inversiones "destrabe" del MEF. La Problemática que arrojó la evaluación en los proyectos de inversión en el Perú, se circunscribieron particular a 2 principales trabas: i) Adquisición (expropiación, etc.) y saneamiento físico -legal de predios y ii) Títulos habilitantes, permisos y licencias que debía dar el Estado, sobre todo en temática ambiental y municipal. Para corregir ello, se emite el Decreto Legislativo del Marco de Promoción de la Inversión Privada mediante Asociaciones Público Privadas y Proyectos en Activos (Decreto Legislativo N. ${ }^{\circ}$ 1224, 2015).

\subsection{1 ¿Es la APP un sistema eficiente en el Perú?}

La respuesta es ciertamente que es un sistema perfectible y que debe irse ajustando en el tiempo. Para Alonso Segura Vasi, los problemas actuales de las APP están en la ejecución de los proyectos. El Economista Segura considera que debe establecerse un gran Plan Estratégico Nacional de Priorización de Proyectos de Inversión en Infraestructura a nivel País, en base a un Plan Multianual de Infraestructura de cada sector, y definir claramente los roles y funciones de cada uno de los actores. Igualmente, no está en la Ley, pero se debe establecer un proceso de estandarización de contratos y de cláusulas contractuales estándares. 
Bajo esta lógica planteada por Segura se puede advertir que anteriormente, los proyectos que se aprobaban y se decidían promocionar y ejecutar por los Gobiernos de turno obedecían más a criterios políticos mediáticos que a criterios técnicos de infraestructura y servicios públicos, es decir, no respondían a un Plan Estratégico Nacional a mediano y largo plazo. Por ello, Segura menciona que el Plan Nacional debe responder a la brecha de necesidad en infraestructura, para luego realizarse un "Informe de Evaluación" (se recogió de la experiencia de Inglaterra y Canadá mayoritariamente a lo que se adecuara mejor al Perú) que contenga ciertos criterios y cumplir ciertos requisitos importantes (presupuestales, financieros, impacto social, ambiental, etc. que están recogidos en el reglamento de APP); este informe, refiere Segura, es un caso de negocios (un business case), es decir, responder a la pregunta de por qué tendría que entrar ese proyecto a promoción por parte de PROINVERSION, el proyecto debe pasar este filtro.

Dentro de estos requisitos, está el criterio "Valor por dinero", este surge en función al resultado de la distribución de riesgos. El "Informe de Riesgos", como refiere Segura, es aquel por el cual se distribuirá ex ante, el riesgo del privado, cual asume el Estado, cuales, compartidos, siendo entre los riesgos más importantes, los constructivos, de diseño financieros, y deberá asumirlos, quien este en mejor posición para hacerlo, Segura considera que ésta es una buena forma de contrarrestar la corrupción, pues a veces concursaban ciertas empresas presentando una matriz de riesgos muy genérica y luego cuando ganaban el proyecto, la variaban mediante adendas. Frente al perfil del SNIP, (hoy INVIERTE PE), Segura advierte, que un sistema metodológico que analiza si cumple con los requisitos como un check list, pero no te priorizará si debe ir o no frente a otro proyecto más importante.

Asimismo, Segura reafirma que la normativa ya establece que no debe cambiar mediante adendas, por ejemplo: i) las condiciones de competencia; ii) el equilibrio económico-financiero; $y$, iii) la matriz de riesgos en principio, salvo casos debidamente sustentados.

Son dos las principales sugerencias que menciona Segura, respecto de la primera, refiere que, al inicio del proceso, la empresa debería presentar el modelo

\footnotetext{
${ }^{5}$ Existe una matriz de riesgos y se aplica una directiva de riesgos que establece todos los riesgos que debe haber en las APP, que contiene una plantilla modelo. No es rígida, se puede modificar, pero se debe sustentar porque del cambio.
} 
económico financiero lacrado al concursar y luego al ganar el proyecto y, en caso quiera una adenda por bancabilidad, se debe abrir. En segundo lugar, se debería establecer una estandarización de las cláusulas contractuales; es decir, cláusulas estándares, se debe quitar las malas y colocar las buenas. La idea sería que lo hiciera el MEF conjuntamente con PROINVERSION.

Finalmente, Segura (entrevista personal, 2017) sentencia: el Sistema de APP es bueno, pero depende cómo se maneja y quien lo maneja. En su opinión, se debería eliminar de la normativa de la APP, las iniciativas privadas, pues no se puede entregar arterias principales de la ciudad a una empresa que nunca llegaría a competir en un concurso y que responde a un interés particular y no a una necesidad pública de prioridad del Estado enmarcado en su Plan Estratégico. Para Segura, uno debe partir y terminar entendiendo el concepto fundamental de las APP:

La APP es una herramienta de política pública para mejorar los servicios públicos y que tienen que responder a Planes Integrales, es una buena y eficiente herramienta, pero si es mal usada, las consecuencias pueden ser letales, un arma letal. Una APP con tarifas pero que genere infraestructura nueva (capacidad adicional a la ciudad) y otra es una APP sustituya y privatice la capacidad existente, la infraestructura ya existente (peaje por by pass y pasar en menor tiempo), no se soluciona el problema público del transporte. (Ejemplo túnel centinela).

2.2.2 ¿Renégociar los contratos y suscribir adendas, abre la puerta a la corrupción? ¿Limitando esta posibilidad como lo ha recogido la reciente modificación del reglamento de APP, será una herramienta efectiva que reducirá la corrupción?

El especialista René Cornejo Díaz (entrevista personal, mayo de 2017) refiere:

El problema de la corrupción está presente en la medida que cualquier eslabón del proceso de contratación genere espacios de discrecionalidad. Desde la concepción del proyecto hasta la terminación del contrato de APP. Las adendas en particular, en la medida que suponen una negociación pueden constituirse en procesos más frágiles por la dependencia de pocos actores y la complejidad de las negociaciones. Sin embargo, por esa misma razón los controles podrían ser más efectivos al acotarse los actores y el ámbito de intervención. Las adendas son inevitables por la duración de los contratos y las limitaciones estructurales en la concurrencia de postores que determinan que los 
contratos tengan limitaciones y sesgos que suman a la principal debilidad que es la poca preparación de los proyectos en el caso de la modalidad de Licitación Pública Especial y las carencias de contraparte y regulatorias en la modalidad de Concurso de Proyectos Integrales, es decir, en proyectos más sencillos y de menor inversión (menores a US\$ 200 millones), las carencias en la preparación técnica y la estructuración del proyecto pueden ser paliadas con la experiencia acumulada y la mayor concurrencia de postores. Es el caso de las líneas de transmisión eléctrica, telecomunicaciones o carreteras más pequeñas. En los proyectos más complejos o más grandes, la limitada capacidad del Estado para hacer la preinversion y la estructuración suponen una debilidad estructural que implica un mayor riesgo para el proceso y les expone a mayores variaciones, mayor número de eventos no previstos y por tanto mayor probabilidad de eventos de Renégociación.

Para Alonso Segura Vasi (entrevista personal, mayo de 2017):

Cuando hay mucha discrecionalidad, facilita la corrupción. Son contratos complejos de una relación de 30 a 40 años, tampoco es prohibir las adendas, no todas las adendas son truchas. Hay imprevistos y cambios de situaciones durante la vida del proyecto de largos años. Delimitar mejor los procesos para acotar la discrecionalidad de los funcionarios. Las adendas no deben cambiar las condiciones de competencia, solo proceden y dentro de los primeros 3 años en: i) errores materiales, ii) precisar temas operativos que impidan ejecutar el contrato iii) incapacidad de cierre financiero (bancabilidad del proyecto). La última ha sido recientemente cambiada a raíz del caso del Aeropuerto Chincheros y ahora procede por hechos sobrevinientes a la buena pro que generan modificaciones imprescindibles para la ejecución del proyecto. El factor humano nunca se va a poder controlar si interpretas arbitrariamente.

Como podemos advertir de los comentarios de ambos expertos es que coinciden que, ante mayor discrecionalidad del funcionario público, mayor campo de acción para los actos de corrupción. De otro lado, si bien observamos que la mayor y compleja problemática se da en la ejecución del contrato, ello se produce por una mala estructuración del proyecto al inicio por parte de la empresa y la incapacidad de análisis y evaluación técnica de los mismos por parte del Estado. Finalmente no se puede concretar el objetivo del proyecto. Respecto de las adendas, ya nuestra normativa ha planteado la oportunidad y causales (solo tres) en las que proceden las adendas. Igualmente consideramos que la segunda y última causal parecen ser muy genéricas y podrían incluirse muchos supuestos, quizás debieran establecerse ciertos parámetros y 
sólo al apartarse excepcionalmente de los mismos, deberá justificarse el por qué de la excepción.

\subsubsection{En qué casos el Estado debe apostar por una APP y no por el sistema de obras públicas. ¿Cuál es el criterio determinante para tomar tal decisión?}

Para Alonso Segura Vasi es con base al criterio técnico: Análisis y aplicación de "valor por dinero", cual arroja mayores beneficios a la ciudadanía y por ende al Estado. Analizar elementos cuantitativos y cualitativos que permiten definir cuál arroja mayores beneficios a la población y al Estado como contraparte. Dentro de este criterio, hay escalas mínimas sectoriales. Considera que no se debe aplicar APP en proyectos muy chicos, dependiendo del sector pues el costo es muy alto.

Igualmente comparte esta misma óptica René Cornejo Díaz (entrevista personal, mayo de 2017), quien refiere que:

Los proyectos más grandes difícilmente pueden ser abordados por el Estado mediante los mecanismos convencionales de obra pública. Lo que debería hacerse es dotar de más recursos (presupuestos, personal y plazos) a los proyectos complejos y de mayor envergadura. La limitación para que esto se aplique es la duración de los mandatos políticos. Cualquier proyecto de una inversión mayor a US\$ 500 millones tendrá un proceso de preinversión y promoción que durará, desde su concepción hasta la suscripción, no menos de 5 años, y dependiendo de la problemática, puede extenderse hasta 8 o 10 años. Ello implica que una buena práctica institucional es que un gobierno prepare los proyectos que la siguiente administración otorgará.

Segura concluye que el riesgo de financiamiento y el riesgo constructivo en una obra pública, ambas la asumen el Estado. En una APP pura, ambas deben ser asumidas por el privado. A la fecha el Perú no cuenta con algún antecedente de APP pura.

Parece estar claro, conceptualmente, cuando procede ingresar un proyecto al sistema de APP y cuando debiera ser tramitado como obra pública, pero lo que parece no estar claro para las autoridades gubernamentales (léase MEF y PROINVERSION); es la aplicación de los criterios técnicos que arrojen estos resultados, es decir, realizar este comparativo y poder evaluar, cuál de los dos sistemas, es el que resulta más beneficioso para la población y a los recursos públicos del Estado. El especialista y 
consultor en APP, Jaime Betalleluz Fernandini, refirió en una disertación ${ }^{6}$ en marzo del 2017, que, si bien el criterio "Valor por dinero estaba recogido en las normas de APP, este no se venía aplicando en la práctica”.

\subsection{Cláusula anticorrupción en el reglamento de la Ley de APP: Análisis y efectos}

Para ello vamos a empezar refiriéndonos a los recientes cambios normativos, específicamente, a la obligatoriedad de incluir en todos los contratos en la modalidad de APP, una cláusula anticorrupción, pero sin precisar el texto de la misma.

Ello no significaba la indefensión del Estado, ya que, ante un caso de corrupción, el Estado contaba con los mecanismos del Código Penal (responsabilidad penal) tanto del funcionario del Estado corrupto y de la empresa jurídica, directivos o trabajadores. Sin perjuicio del inicio del procedimiento administrativo disciplinario al funcionario corrupto (responsabilidad administrativa) y proceso de despido por falta grave a los funcionarios de la empresa privada corrupta y, sin perjuicio de las demandas civiles por daños y perjuicios contra el funcionario y contra la empresa o funcionario de la empresa (responsabilidad civil).

Uno de los recientes cambios a nivel normativo ha sido justamente, la incorporación del artículo 61 A mediante el Decreto Supremo N. ${ }^{\circ}$ 068-2017-EF (2017) que modifica el reglamento de las APP, y que a la letra dice:

Artículo 61 A.- Cláusula Anticorrupción.

En el diseño de la versión del contrato durante la fase de Estructuración, se debe incluir una cláusula anticorrupción, bajo causal de nulidad.

Artículo 63.- Terminación.

\footnotetext{
${ }^{6}$ Seminario de Actualización. (23 de marzo 2017). Nueva Legislación 2017: Asociaciones Publico Privadas APP y Obras Por Impuestos.
} 
Del análisis de la incorporación de la tan anunciada cláusula anticorrupción por parte del Poder Ejecutivo, consideramos un error, no haber recogido el texto mínimo que debe contener dicha cláusula o cláusula modelo y que debió ser imperativo, el contemplarla, en todos los modelos de contratos de APP. Es decir, el reglamento debió recoger la fórmula similar de la "cláusula tipo", como lo recogiera la normativa de contrataciones del Estado, que en el artículo 40 de la Ley de Contrataciones del Estado (Decreto Legislativo N. ${ }^{\circ}$ 1017, 2008) establece no solo cuales son las cláusulas obligatorias que necesariamente debe contener el contrato, bajo responsabilidad, entre ellas, la cláusula sobre solución de controversias (literal b), sino que sanciona y sentencia, que de no incorporarse la cláusula de arbitraje en las bases o en el contrato, se entenderá que se incluye de pleno derecho, la cláusula modelo de arbitraje que contemple el reglamento. Por su parte, el Reglamento de la Ley de Contrataciones del Estado (Decreto Supremo N. ${ }^{\circ}$ 184-2008-EF, 2008) en el artículo 216, cuarto párrafo, contempla que, de no haberse incorporado en el contrato, el convenio arbitral, se incorpora de pleno derecho el siguiente texto:

Todos los conflictos que se deriven de la ejecución e interpretación del presente contrato, incluido los que se refieran a su nulidad o invalidez, serán resueltos de manera definitiva e inapelable mediante arbitraje de derecho, de conformidad con lo establecido en la normativa de contrataciones del Estado, bajo la organización y administración de los órganos del sistema nacional de arbitraje del OSCE y de acuerdo a su reglamento.

Surge entonces la interrogante: ¿en qué medida dicha obligación va a servir en la práctica para evitar que se filtre la corrupción en los procesos de APP, entorpezca la ejecución de éstos y mine la confianza de la población en dicho mecanismo, incluso de los futuros inversionistas?

\subsubsection{Contenido mínimo de la cláusula anticorrupción en los contratos de Inversión}

Antes de que existiera el mandato legal de hacerlo, el incluir una cláusula anticorrupción era discrecional en el Perú y no se utilizaba en la mayoría de contratos por falta de una política de Estado al respecto. Su uso estaba más difundido en el sector energía. 
Como lo refiere el abogado Miguel Ángel Ronceros en su artículo "Contratos y cláusulas anticorrupción" los primeros contratos en contemplar cláusulas anticorrupción datan del año 2000, en los contratos de concesión de transporte de gas natural y líquidos de Camisea.

Luego, posteriormente, por ejemplo, el contrato de Concesión del gaseoducto del sur peruano (GSP), suscrito en mayo del 2014, también contó con una cláusula anticorrupción, que a la letra dice:

Cláusula 5: Declaraciones del Concedente y Concesionario

5.1 Declaraciones del Concesionario.

5.1.6 Pago Indebido:

Que el Concesionario, ninguno de sus accionistas, socios o Empresas Vinculadas, ni cuales quiera de sus respectivos directores, funcionarios, empleados, asesores, representantes legales o agentes, ha pagado, recibido, ofrecido, ni intentado pagar o recibir u ofrecer, ni intenta pagar o recibir u ofrecer en el futuro ningún pago o comisión ilegal en relación con la Concesión, el Contrato y el Concurso.

Del análisis del párrafo citado, se entiende que, esta declaración del Concesionario, tiene la calidad de declaración jurada, en la que garantiza que ni él, ni las personas naturales o jurídicas vinculadas a él o con él, comercial, laboral y/o societariamente han recibido, pagado ofrecido, ni vienen recibiendo, pagando u ofreciendo, ni intentaran recibir, pagar u ofrecer pago o comisión ilegal alguna. Este es, más que un compromiso, una obligación del Concesionario de cumplir y hacer cumplir con transparencia los procedimientos y normativa aplicable. Cabe precisar que esta obligación incluso se quiebra con la intencionalidad, es decir con la tentativa.

En caso de incumplirse con esta obligación del Concesionario, tendrá que aplicarse complementariamente las disposiciones de la Cláusula 20 sobre la Terminación de la Concesión:

Cláusula 20.- Terminación de la Concesión y Transferencia de los Bienes de la Concesión.

20.1 La terminación de la Concesión ocurría por las siguientes causales:

C.6. La Falsedad de cualquiera de las declaraciones y garantías efectuadas por el Concesionario o por el Operador Calificado, conforme a lo establecido en el presente Contrato, en el Concurso o durante la ejecución del Contrato. 
En consecuencia, al descubrirse y acreditarse que el concesionario o las personas naturales o jurídicas vinculadas a él o con él comercial, laboral y/o societariamente, cometieron un acto de corrupción o lo intentaron, esta declaración, se entenderá que ha sido falsa, correspondiendo al Concedente, es decir, al Estado Peruano, a dar por terminada la Concesión.

Otro ejemplo, es el Contrato de Concesión de la Longitudinal de la Sierra suscrito en junio del 2015, el cual contempla otro tipo de cláusula, refiriendo directamente a los actos dolosos e ilegales, según lo establece la Cláusula XVI:

\section{CAPÍTULO XVI: CADUCIDAD DE LA CONCESIÓN}

\section{TERMINACIÓN DEL CONTRATO}

16.1. La presente Concesión caducará por la verificación de alguna de las siguientes causales:

c) Resolución del Contrato por incumplimiento del CONCESIONARIO.

\subsection{TÉRMINO POR INCUMPLIMIENTO DEL CONCESIONARIO}

d) La comisión de cualquier acto u omisión que constituya incumplimiento doloso del CONCESIONARIO que derivase en la comisión de un delito de acción pública en perjuicio del Usuario, del CONCEDENTE y/o del REGULADOR, cuando así lo disponga una sentencia con calidad de cosa juzgada.

Si bien esta cláusula de resolución del contrato, refiere a cualquier acto u omisión dolosa que configure un delito, previa sentencia, solo refiere directamente al Concesionario y no a las personas naturales o jurídicas vinculadas a él o con él comercial, laboral y/o societariamente.

\subsubsection{Efectos de la aplicación de la cláusula Anticorrupción}

Actualmente se viene discutiendo en los medios de comunicación en particular, sobre los efectos de dar por finalizados los contratos de los megaproyectos, a raíz del caso de corrupción con la empresa brasileña Odebrecht, debido a la paralización de las obras como es el caso del Gasoducto Sur Peruano, Chavimochic, Majes y el Alto Piura. Incluso, el gremio de construcción civil, le ha reclamado al Estado peruano, que, si 
bien, se debe ser implacable contra la corrupción, se busque alternativas que no impliquen paralizar las obras, sino por el contrario, reactivarlas, ya que contabilizando la paralización de los cuatro (04) megaproyectos, se estiman 15,000 puestos de trabajo de obreros perdidos. (Diario Gestión del 28 de enero de 2017). En esta coyuntura, el Presidente de la República, Pedro Pablo Kuczynski (PPK), manifestó que preferiría relicitar el Gaseoducto Sur Peruano, es decir, sacar una nueva licitación. Como se sabe, previo a sacar una nueva licitación, el Poder Ejecutivo deberá subastar el proyecto y luego pagarles a las empresas por orden de prelación. (Diario Gestión del 26 de enero de 2017).

\subsection{3 ¿Es la cláusula anticorrupción un arma letal o de doble filo?}

Para Alonso Segura Vasi, la cláusula anticorrupción es un arma de doble filo, es draconiana por la sanción de nulidad del contrato y por ende al proyecto. Segura considera que quizá sería válido, que se pueda aplicar estableciendo el nivel o gradualidad de corrupción como el caso de Odebrecht o si es periférico al proceso, es decir, de un funcionario de cuarto nivel del Estado y/o cuarto nivel del contratista que por ejemplo recibió S/ 5,000 soles, ¿igual debes resolver el contrato y se cae un megaproyecto de miles y miles de dólares? Por ejemplo, el caso del Gaseoducto Sur Peruano (GSP), no pudieron presentar el cierre financiero y se fue a la causal de resolución del contrato. Pero no logró el cierre financiero porque este contrato tenía cláusula anticorrupción.

Precísese que para Segura (entrevista personal, mayo de 2017): "El cierre financiero es la presentación de una estructura de financiamiento para el proyecto antes del inicio de obra, es cómo se va a financiar".

Actualmente, ¿se ha demostrado o declarado corrupción en este proyecto? La respuesta es No, pero la siguiente pregunta es ¿quién entra a comprar los activos de Odebrecht con una cláusula anticorrupción? y pide financiamiento al sistema financiero, pero el consorcio de Bancos condiciona otorgarlo, pidiendo sacar la cláusula anticorrupción. El Gobierno no aceptó retirar la cláusula y se cayó el proyecto, por el solo hecho de existir la posibilidad que lo hubiera o pudiese presentarse potencialmente. El efecto ante el solo riesgo de corrupción es el mismo que existiera corrupción: se tira 
abajo el contrato. Por el solo hecho de la incertidumbre, se paralizan y se caen los contratos. Es un riesgo no mitigable en términos económicos.

Si bien para Segura, es un disuasivo, pero tiene efectos adversos y un efecto dominó en la cadena de proveedores y en todos los diversos proyectos que puedan tener una empresa declarada corrupta y/o los efectos de incluir a la otra empresa consorciada. Efectos perversos. Segura considera que hay otros mecanismos (planes multianuales, planes de infraestructura, informes de evaluación, informes de riesgos, publicaciones de pedidos de adendas, especificar claramente las causales que son adendables, guardar el modelo económico financiero, criterios de competencia inmodificables y cláusulas estandarizadas, etc.) más eficientes para limitar el campo de cultivo del cual surge la corrupción.

\subsubsection{Resolución de los contratos como alternativa}

Analizando cual es la finalidad de contemplar obligatoriamente una cláusula anticorrupción en los contratos de inversión público-privada, consideramos que es una de disuasión. Pero si deseamos una disuasión efectiva, la sanción de cometer un acto de corrupción, solo puede y debe ser, la de resolver el contrato. Es decir, los efectos o consecuencias por cometer actos de corrupción deben ser letales, a costa de paralizar la obra por meses o quizás años y tener que volver a solicitar y evaluar a un nuevo inversor que retome la obra donde se quedó. Esta medida disuasiva, busca que la empresa reflexione y prevea dejar de hacer algo (corruptela), que, de hacerlo, traería como consecuencia drástica, la resolución del contrato y con ello otras consecuencias de responsabilidades civiles y penales.

\subsubsection{La Cesión de Posición Contractual como alternativa de mantener vigente el Contrato}

Por otro lado, cabría otra alternativa, que es, que, la Cláusula Anticorrupción, contemple que el Estado, "podrá" dar por terminado el Contrato en caso de actos de corrupción. En este caso, el Estado tendría la facultad de declarar o no la resolución del contrato. Este supuesto tendría mayor sentido en un esquema donde el Concesionario es un Consorcio y se acredita que solo una empresa del consorcio es la que ha cometido actos de corrupción o declara que los cometió. Solo bajo este supuesto, el Estado, en 
aras de darle continuidad al proyecto, podría decidir que no se resuelva el contrato y que se proceda con una cesión de posición contractual a una nueva empresa que formara parte del consorcio, contando previamente con la autorización y aprobación del Estado y de la empresa consorciada no culpable que permanecerá en el contrato. Consideramos que, igualmente, la obra podría paralizarse por un determinado tiempo hasta que ingrese la nueva empresa cesionaria, pero estimamos que definitivamente, dicho tiempo siempre será menor al que tomaría, realizar una nueva convocatoria o presentación de intereses y/o de iniciativas privadas: "Relicitar".

Bajo este esquema, de darle al Estado un criterio discrecional de decidir si se resuelve o no el contrato, definitivamente, le resta finalidad disuasiva, a la cláusula anticorrupción.

Por consiguiente, dependiendo si la cláusula le permite al Estado, ante un acto de corrupción o reconocimiento de este, evaluar si da por resuelto el contrato, consideramos relevante que se establezcan parámetros y criterios objetivos a nivel reglamentario normativo, que permitan una evaluación técnica, económica, social y hasta política que permita determinar en qué supuestos debe el Estado optar por continuar con el contrato y por consiguiente con la obra o servicios, vía cesión de posición contractual, o, por el contrario, en que supuestos deberá dar por resuelto el contrato.

A la luz de la reciente modificación del Reglamento de la Ley de APP (Decreto Supremo N. ${ }^{\circ}$ 068-2017-EF, 2017), que incorpora la obligatoriedad de incluir la cláusula anticorrupción en todos los contratos de APP, bajo sanción de nulidad, este texto deja abierta la opción del Estado de redactar el texto de la cláusula en cualquiera de los dos sentidos: i) el Estado podrá dar por resuelto el contrato ó ii) el Estado deberá dar por resuelto el contrato.

\subsection{6 ¿Qué otras características deberían contemplar una cláusula anticorrupción efectiva?}

Para René Cornejo Díaz (entrevista personal, mayo de 2017), una buena cláusula anticorrupción debiera contener las siguientes características para que sea efectiva y no se quede en el papel: 
a) Definir con precisión cuando se aplica, es decir, cuando se verifica que se ha dado la corrupción a efectos de aplicar la cláusula. Podría contener un procedimiento que incluya acciones preventivas, como una subrogación en la administración de los flujos.

b) El efecto de la cláusula debería ser de nulidad del contrato y ejecución de una carta fianza (que podría ser la misma de fiel cumplimiento, aunque su redacción debiera ser expresa en cuanto a la aplicación de la cláusula de caducidad).

c) Debe establecer con claridad las acciones sobrevinientes que permitan la continuidad del servicio público asociado a la APP.

d) Debe establecerse con claridad el destino del remanente patrimonial de la sociedad concesionaria. En principio debiera ser mantenido como respaldo de una eventual responsabilidad civil por el delito de corrupción.

Quizá sería válido, que se pueda aplicar la cláusula anticorrupción, pero estableciendo el nivel o gradualidad de corrupción, que te permita analizar dependiendo de la escala de corrupción (nivel alto tipo Odebrecht) o si es periférico al proceso. (Alonso Segura Vasi, 2017).

En ese sentido, nuevamente estaríamos dejando a criterio discrecional de los funcionarios, evaluar la magnitud y nivel de corrupción para que, en función de ello, puedan tomar la decisión de resolver el contrato o, por el contrario, sancionar a los corruptos, pero mantener el proyecto. Quizá podría precisarse expresamente y objetivamente en un reglamento, los casos en los cuales procede la resolución inmediata del contrato y en qué casos procede la cesión de posición contractual para que prosiga el proyecto en la etapa donde se quedó.

En la normativa sobre Política Anticorrupción Chilena y Probidad de los negocios $^{7}$, se establece un breve procedimiento que ante un indicio o acto de corrupción, ambas partes se deberán comunicar inmediatamente el hecho o potencial acto y tomar todas las acciones o medidas correctivas para evitarlo o remediarlo o sancionarlo, pero sí la violación es de tal magnitud que dañe o potencialmente pudiese dañar la reputación del Estado, empresa o gravemente pueda afectar la efectividad o calidad de los servicios u obra materia del Contrato, el Estado podrá en forma

\footnotetext{
${ }^{7}$ La Ley sobre Probidad Administrativa N. ${ }^{\circ} 19.653$, la Ley N. ${ }^{\circ} 20.169$ que previene la Competencia Desleal, la Convención de las Naciones Unidas contra la Corrupción, ratificada por Chile el 13 de septiembre de 2006 y la Convención Interamericana contra la Corrupción, ratificada por Chile el 22 de septiembre de 1998. la Ley N. ${ }^{\circ} 20.393$ de Chile, que establece la Responsabilidad Penal de las Personas Jurídicas en los delitos de Lavado de Activos, Financiamiento del Terrorismo y Delitos de Cohecho. https://www.cl.issworld.com/responsibility/politicadeanticorrupcion.
} 
automática dar por terminado el Contrato y no tendrá que pagar indemnización alguna a la empresa.

Consideramos que la cláusula anticorrupción debiera contener cuáles son los actos típicos de corrupción que pueden ser considerados como irregularidades en las compras, adquisiciones y/o proyectos de inversión del Estado de manera enunciativa, más no limitativa o restrictiva, pues como sabemos con la tecnología se ingenian nuevas formas de corrupción. En ese sentido, se debe comprender, entre otros, los siguientes actos: i) recibir y aceptar por el servidor público, productos defectuosos; ii) contrataciones sin seguir el proceso de selección que corresponda; iii) direccionar el proceso a un proveedor o contratista en particular; iv) incumplir plazos y no aplicar penalidades por incumplimiento o cumplimiento tardío; v) efectuar obras sin los estudios previos; vi) sobrevalorar obras o servicios, recibir y aprobar obras o servicios ó construcciones con defectos; vii) pagar por servicios que no se hubieran realizados; viii) contratar personal que no cumpliría el perfil del puesto; ix) nepotismo en la contratación del servidor público o del contratista o adquiriente o concesionario; y, x) utilizar en forma indebida los materiales, maquinarias o fondos de las contrataciones del Estado.

\subsection{7 ¿Es suficiente una cláusula anticorrupción?, ¿Que otras medidas o acciones se necesitaría implementar para evitar los casos de corrupción en el marco de la APP, es por deficiencia de una legislación adecuada o hay otros factores que influyen?}

Este trabajo de investigación no estaría completo si se limitara a únicamente a evaluar y proponer mejoras a nivel normativo de las APP, en particular con una cláusula anticorrupción, ya que existen falencias indiscutibles a nivel de capacidades institucionales y de gestión. Por ello, se requiere fortalecer todo el proceso, es decir, todo el sistema en forma integral y no solo el marco normativo. En ese sentido a nivel gestión se requiere:

Contar con un Plan de Infraestructura a 20 años que permita ordenar el proceso de preinversión y la programación presupuestal necesaria" y complementariamente "se requiere fortalecer TODO el proceso en particular: 
a) PREINVERSIÓN: No lanzar el proyecto hasta tener un estudio de factibilidad. Si se opta por la modalidad de Licitación Publica Especial, debe contarse con el proyecto definitivo (proyecto de ingeniería).

b) ESTRUCTURACIÓN DEL PROYECTO: Con una buena preinversion es mucho más probable lograr una estructura y contrato financiable y atractivo para el mercado.

c) PREPARACIÓN DEL PROCESO: Una buena preinversion permitirá a los inversionistas contar con información del proyecto suficiente para hacer ofertas con inversiones poco cuantiosas lo cual atraerá a mas inversionistas. Asimismo, permitirá una mejor estimación de los riesgos. Por último, el cronograma será más creíble y lograble.

d) PROMOCIÓN Y CONCURSO: Se necesita una agresiva campaña de promoción del proceso atrayendo a inversionistas de distintos países. La mejor base para un buen contrato es un concurso que convoque y logre una mayor cantidad de postores (lograr más de 05 es muy difícil pues el incentivo para ingresar, sobre todo a nuevos inversionistas es muy pequeño al tener reducidas posibilidades de ganar el concurso). Esto permitirá un mejor contrato y por tanto reducirá las probabilidades de necesitar adendas y a su vez, la amplitud de las mismas estaría acotada. (René Cornejo Díaz, 2017)

Es un tema de incorporar incentivos en el sistema que induzca a comportamientos correctos, como, por ejemplo:

Plan Multianual, Plan Estratégico de Priorización de Proyectos Infraestructura, Banco de Proyectos, Informe de Evaluación, Evaluación de Riesgos, Causales para otorgar adendas, publicación de versiones de adendas, presentación de la estructura del modelo financiero, ampliar en las iniciativas privadas mayor margen de competencia, entre otros. (Alonso Segura Vasi, 2017)

Compartimos la opinión de ambos expertos y en particular el tema de desarrollo de capacidades desde el sector estatal, es fundamental para tener un sistema normativo, de gestión y ejecución de primer nivel. Empezando por fortalecer a los especialista funcionarios que deben integrar equipos multidisciplinarios, no solo de cada sector, sino también en PROINVERSION, Contraloría General de la República, Reguladoras y el propio MEF. 


\section{CAPÍTULO III: PROPUESTA DE ESTANDARIZACIÓN DE LA CLÁUSULA ANTICORRUPCIÓN EN LA INVERSIÓN PRIVADA, PARTICULARMENTE EN LA}

APP

\subsection{Introducción}

La Contraloría General de la República mencionó a través de su Contralor en los medios de prensa en febrero del 2017, la imperiosa necesidad de establecer por Ley, la obligatoriedad de colocar la cláusula anticorrupción en todos los contratos de inversión privada en infraestructura pública y en las bases de los concursos y no solo, como se había venido dando, en algunos contratos de concesión en hidrocarburos. El Poder Ejecutivo, en especial el Ministerio de Economía y Finanzas conjuntamente con PROINVERSION, analizaron una propuesta en ese sentido. Finalmente, esta llegó con la modificación de la reglamentación de la Ley de APP con el Decreto Supremo N. ${ }^{\circ}$ 068-2017-EF (2017), que como lo comentáramos en el numeral 2.3 del Capítulo II, incorporó el artículo 61.-A, que dispone la obligatoriedad de contemplar una cláusula anticorrupción en todos los modelos de contratos de APP, bajo sanción de nulidad.

Consideramos que el Poder Ejecutivo, como lo explicamos en el Capítulo II del presente trabajo de investigación, debió contemplar la cláusula tipo que debe incluirse en todo contrato de APP y que, de no hacerlo, sin perjuicio de la responsabilidad funcional de los servidores públicos que la omitieran, se entiende incorporada en el contrato, de pleno derecho automáticamente, el texto de la norma.

Asimismo, la cláusula tipo, debió establecer si la resolución del contrato estaba librada a una facultad del Estado de poder resolver o era imperativa e inmediata ante el acto o declaración de corrupción. En todo caso, también se pudo optar por una fórmula mixta que contemple que en ciertos supuestos de corrupción, aplicando ciertos criterios objetivos, técnicos, económicos y sociales, el Estado deba resolver el contrato en los casos más gravosos y si por el contrario se trataría de actos de corrupción menores y/o que afecta a un número significativo de la población que se iba a ver beneficiada con el 
proyecto que el valor económico del proyecto supere una cantidad "x" de UIT, si podría mantener vigente el contrato y se proceda a una cesión de posición contractual.

Conforme a lo expuesto, proponemos un texto de cláusula tipo que permita ser aplicada en todos los contratos del Estado, en particular en los contratos de APP.

Es importante establecer en el contrato y previamente en la normativa de APP, el otorgamiento de una garantía, en este caso, podría ser una carta fianza equivalente al 4\% del valor del proyecto con las características de la carta fianza de fiel cumplimiento del resto de obligaciones contractuales. Asimismo, al momento de presentación de los documentos para la firma del contrato, la empresa deberá firmar una cesión de posición contractual a la empresa que el Estado designe posteriormente, en caso el Estado invoque la cláusula anticorrupción y opte por la cesión de posición contractual ante algún caso de corrupción que amerite que el proyecto continúe.

\subsection{Cláusula Anticorrupción Propuesta}

El texto propuesto sería:

1.1 El Contratista/Cesionario/Consorcio/ Inversionista declara que ni el cómo empresa ni ninguno de sus accionistas, socios o empresas vinculadas o del mismo grupo económico ni ninguno de sus directores, gerentes, funcionarios, asesores internos o externos, representantes, representantes legales, agentes, trabajadores de la empresa o de las personas jurídicas antes citadas o de las personas naturales o jurídicas con las que tienen relaciones directa o indirecta de propiedad, vinculación o control, no han participado ni directa o indirectamente en prácticas o actos corruptos, es decir, no han autorizado, aceptado, solicitado, pagado, entregado, coordinado, ofrecido, recibido, ni intentado pagar, recibir u ofrecer ningún pago o comisión ilícita o ilegal o alguna dadiva, bien mueble o inmueble, ventaja ilícita sea pecuniaria, económica o similar y en general cualquier beneficio o incentivo ilegal en relación con y/o antes, durante la etapa de los actos preparatorios, fases del proceso convocatoria, propuesta del proyecto, firma del contrato y/o durante la ejecución del contrato. Asimismo, la empresa y sus asociados, accionistas y demás mencionados en este numeral 1.1, se obligan a conducirse antes y durante la convocatoria, proceso y contrato y ejecución del mismo, con integridad, honestidad, veracidad y no cometer actos corruptos o ilegales. 
1.1.1 Asimismo, las partes acuerdan que, de presentarse indicios, potenciales actos $u$ actos de corrupción menores ${ }^{8}$ por parte de sus subalternos o trabajadores, comunicaran inmediatamente dentro de las 24 horas de tomar conocimiento del mismo, a la otra parte y se comprometen a tomar acciones preventivas, correctivas o sancionadoras y comunicarlas en igual plazo.

1.1.2 Se entenderán actos de corrupción, en forma enunciativa, mas no excluyente o limitativa, los delitos tipificados en la sección IV del Capítulo II del Título XVIII del Código Penal Peruano, así como los siguientes actos: i) recibir y aceptar por el servidor público o funcionario de la empresa, cualquier dinero, bien, dadiva, beneficio o incluso aceptar productos defectuosos, ii) contrataciones sin seguir el proceso y procedimientos de selección que corresponda, ii) direccionar o pedir que se direccione el proceso a una empresa en particular, iii) incumplir plazos y no aplicar penalidades por incumplimiento o cumplimiento tardío, iv) efectuar obras sin los estudios previos, v) sobrevalorar obras o servicios, recibir y aprobar obras o construcciones con defectos, vi) pagar por servicios que no se hubieran realizados, vii) nepotismo en la contratación del servidor público o del contratista o adquiriente o concesionario, viii) utilizar en forma indebida los materiales, maquinarias o fondos provenientes del erario estatal.

\subsection{El Estado Peruano, queda facultado a optar por el procedimiento de cesión de} posición contractual de la empresa infractora o declarar la Resolución de Pleno derecho del Contrato, para este último caso, sólo procederá cuando la violación o potencial violación se da por parte de la alta dirección de la empresa en el Perú, es decir de los principales directivos, dueños, accionistas o socios de la empresa o consorcio y se trate de una afectación de tal magnitud, que afecte la reputación de la empresa o al Estado o se afecte seriamente la calidad del servicio público objeto del contrato, y que en consecuencia, de conformidad con lo dispuesto en el artículo

\footnotetext{
${ }^{8}$ La normativa deberá precisar cual son actos de corrupción menores que no debieran afectar el proyecto, por ejemplo que un funcionario haya recibido una canasta navideña.
} 
1430 del Código Civil Peruano (Decreto Legislativo N.²95, 1984) en el supuesto que:

A) Por algún acto de corrupción al haber infringido lo establecido en el párrafo precedente, numeral 1.1 y/o por falsedad de cualquiera de las declaraciones y/o garantías efectuadas por la alta dirección del Contratista/Cesionario/Consorcio/Inversionista, según corresponda, conforme a lo establecido en sus propuestas, documentos, el presente contrato o durante la ejecución de alguno de ellos, cuando se verifique la existencia condenatoria, consentida o ejecutoriada por cualquiera de los delitos tipificados en la sección IV del Capítulo II del Título XVIII del Código Penal Peruano o delitos equivalentes en caso estos delitos hayan sido cometidos en nuestro País, contra los accionistas, socios o de empresas vinculadas o del mismo grupo económico, de sus directores, gerentes, funcionarios, asesores internos o externos, representantes, representantes legales, o de las personas jurídicas antes citadas o jurídicas con las que tienen relaciones directa o indirecta de propiedad, vinculación o control, de acuerdo con lo dispuesto en el Reglamento de Propiedad Indirecta, Vinculación y Grupos Económicos de la Resolución SMV N. ${ }^{\circ}$ 019-2015-SMV/01 de la Superintendencia del Mercado de Valores; o,

B) Cuando el Contratista/Cesionario/Consorcio/Inversionista, accionistas, socios o empresas vinculadas o del mismo grupo económico, sus directores, gerentes, funcionarios, asesores internos o externos, representantes, representantes legales, agentes, trabajadores de la empresa o de las personas jurídicas antes citadas o de las personas naturales o jurídicas con las que tienen relaciones directa o indirecta de propiedad, vinculación o control, de acuerdo con lo dispuesto en el Reglamento de Propiedad Indirecta, Vinculación y Grupos Económicos de la Resolución SMV N. ${ }^{\circ}$ 019-2015-SMV/01 de la Superintendencia del Mercado de Valores, admitan y/o reconozcan la comisión de cualesquiera de los delitos tipificados en la Sección IV del 


\section{Capítulo II del Título XVIII del Código Penal Peruano, ante alguna autoridad nacional competente.}

1.3 En cualesquiera de los casos (A) y (B), el Contratista/Cesionario/Consorcio/ Inversionista no tendrá derecho a reembolso o restitución de suma alguna que haya efectuado en el marco del presente Contrato o exigir o reclamar el pago por compensación, daños y perjuicios o indemnización alguna por las inversiones o prestaciones realizadas antes o durante la ejecución del presente contrato, no pudiendo exigir al Estado Peruano ninguno de los conceptos antes mencionados.

1.4 La Garantía Anticorrupción, se entregará por parte del Contratista/Cesionario/Consorcio, a la suscripción del Contrato, la misma que será solidaria, irrevocable, incondicional y de realización automática a solo requerimiento a favor del Estado Peruano, a través de una carta fianza bancaria equivalente al cuatro (04\%) del monto total del Contrato. La Garantía mantendrá su vigencia hasta seis (06) meses después de terminado el contrato.

1.5 Las partes acuerdan que de presentarse el acto de corrupción sea declarado por el Contratista/Cesionario/Consorcio/ Inversionista, de sus personas naturales y/o jurídicas relacionadas o vinculadas o por sentencia consentida y ejecutoriado en el país donde se suscribió el contrato, se procederá a ejecutar la carta fianza por corrupción a favor del Estado", no teniendo la empresa corrupta derecho a indemnización alguna ni devolución de suma entregada o por avance de obra ejecutada".

\subsection{Análisis de la propuesta}

En la cláusula propuesta, recogemos en el numeral 1.1, la declaración de la empresa, en calidad de declaración jurada en la que manifiesta que no ha recibido, ofrecido ni pedido ni intentado ni ella ni ninguno de sus asociados o vinculados dinero o ventajas ilícitas para sí o para algunos de los asociados o vinculados. Debiéndonos remitir a las definiciones sobre cunado se configura la propiedad indirecta, vinculación y grupos 
económicos, establecidas por la Superintendencia de Mercado de Valores, desarrolladas en el Reglamento de Propiedad Indirecta, Vinculación, y Grupos Económicos, aprobado mediante RSMV N. ${ }^{\circ}$ 019-2015-SMV/01:

\section{Artículo $3^{\circ}$.- PROPIEDAD INDIRECTA}

Es propiedad indirecta la que una persona o ente jurídico tiene a través de otras personas o entes jurídicos. Se presume, salvo prueba en contrario, que existe propiedad indirecta en los siguientes casos:

3.1 La propiedad indirecta de una persona natural es la propiedad que directamente corresponde a cada uno de sus parientes, así como la propiedad, directa o indirecta, que corresponde a la persona jurídica o ente jurídico en la que la referida persona natural o sus parientes tienen participación representativa.

3.2 La propiedad indirecta de una persona jurídica o ente jurídico es la propiedad que directamente corresponde a otras entidades sobre las cuales la primera tiene participación representativa; así como la propiedad indirecta que estas últimas tienen, a su vez, a través de otras entidades, siempre que en estas también tengan una participación representativa. Este criterio se aplica de manera sucesiva, siempre que exista participación representativa.

\section{Artículo 5.- PARTES VINCULADAS}

Se presume vinculación, salvo prueba en contrario:

5.1 Por parentesco, entre personas naturales.

5.2 Por propiedad y/o gestión, entre:

5.2.1 Una entidad y las personas o entes jurídicos que tengan participación representativa en esta.

5.2.2 Una entidad y las personas o entes jurídicos que tengan propiedad indirecta en esta, igual o mayor al cuatro (4\%) por ciento.

5.2.3 Las personas naturales que ejercen el control de un mismo grupo económico.

5.2.4 Las entidades de un mismo grupo económico.

5.2.5 Una entidad y la persona, ente jurídico o grupo de personas que controlan a esta o que ejercen el control del grupo económico al que pertenece esta.

5.2.6 Una entidad y las entidades controladas por alguna (s) de las personas naturales que ejercen el control de la entidad o del grupo económico al que pertenece la entidad. 
5.2.7 Una entidad y los parientes de las personas naturales que ejercen el control sobre esta o que ejercen el control del grupo económico al que pertenece esta.

5.2.8 Una entidad y sus directores, principales funcionarios o asesores o quienes hayan desempeñado dichos cargos en los últimos doce (12) meses.

5.2.9 Los directores, principales funcionarios y asesores de una entidad, según corresponda, y los accionistas o socios que tengan participación representativa en dicha entidad.

5.2.10 La persona o ente jurídico a favor de quien se otorgó un financiamiento y el destinatario final a quien se trasladó el mismo, durante el tiempo que se mantenga el financiamiento y hasta doce (12) meses de culminado este.

5.2.11 Una persona o ente jurídico y aquella que la representa, siempre que esta última tenga la capacidad para tomar decisiones en una o más operaciones.

5.2.12 Las entidades que tienen en común a por lo menos un tercio de sus directores o principales funcionarios.

5.2.13 Las personas que tengan suscrito un contrato asociativo, y hasta doce (12) meses posteriores a su finalización.

5.2.14 La persona o ente jurídico acreedor o garante de obligaciones y la persona o ente jurídico deudora o cuyas obligaciones son garantizadas por la primera, siempre que la acreedora o garante no sea una empresa del sistema financiero y dicha acreencia o monto garantizado represente más del diez por ciento (10\%) de los pasivos del deudor.

5.2.15 Las personas o entes jurídicos que tienen obligaciones respaldadas por una misma garantía.

5.2.16 Las personas jurídicas que tienen accionistas o socios comunes que pueden designar o destituir, por lo menos, un tercio de los miembros del directorio en cada una de ellas.

5.2.17 Las personas naturales y las entidades pertenecientes a un grupo económico, cuando las primeras sean directores, principales funcionarios o asesores de una persona o ente jurídico, según corresponda, perteneciente al grupo económico de dicha entidad o hayan ejercido cualquier de estos cargos durante los últimos doce (12) meses.

5.2.18 Una entidad y otra cuando de la documentación institucional de una de ellas o mediante prueba indiciaria se evidencie que una actúa como división o departamento de la otra. 
5.2.19 Las entidades que hayan intercambiado dos (02) o más de sus directores, gerentes y/o principales funcionarios, durante los últimos doce (12) meses.

\section{Artículo 6‥- CONTROL}

Se denomina control a la influencia preponderante y continua en la toma de decisiones de los órganos de gobierno de una persona jurídica u órganos que cumplan la misma finalidad en el caso de un ente jurídico.

Asimismo, en el numeral 1.1.1, se establece un breve procedimiento de poner en conocimiento y tomar acciones inmediatas en los casos que se pueda evitar, remediar o sancionar actos menores de corrupción o potenciales actos de corrupción y encausar correctamente a fin de no afectar el desarrollo del proyecto.

Complementariamente, en el numeral 1.1.2 se describe de manera enunciativa más no excluyente, los posibles actos de corrupción que deben evitarse o encausarse o sancionarse.

En el numeral 1.2 de la cláusula propuesta, se deja a criterio del Estado, el decidir por la cesión de posición contractual o por la resolución del contrato y ejecutar la carta fianza anticorrupción, es decir, al advertirse la existencia de una sentencia por acto de corrupción sea en el Perú o la empresa o sus relacionados o vinculados terminen reconociendo el acto de corrupción en el Perú; se habrá infringido la declaración jurada del numeral 1.1, facultando al Estado a optar por alguna de las dos alternativas.

De otro lado, en este numeral se cita el artículo 1430 del Código Civil Peruano conocido como la "cláusula resolutoria expresa", a fin de precisar en forma expresa, las prestaciones que, de incumplirse por la empresa infractora, configuran las causales A) o B) para que se active la resolución automática de pleno derecho del Contrato. La Causal A) está referida aquellos actos de corrupción con sentencia firme y ejecutoriada y la Causal B) está referida a que la empresa o sus allegados declaren haber cometido actos de corrupción. (Ejemplo reciente, en el 2016-2017 de la empresa brasilera Odebrecht).

Finalmente en este numeral, se mencionan los delitos del Código Penal Peruano (Decreto Legislativo N. $\left.{ }^{\circ} 635,1991\right)$ en el Título XVIII, que están referidos a los llamados "Delitos Contra la Administración Pública", igualmente, el Capítulo II está referido a los "Delitos cometidos por funcionarios públicos" y finalmente, la Sección IV está referida a los "Delitos de Corrupción de Funcionarios" siendo los siguientes: 
Artículo 393.- Cohecho pasivo propio; Artículo 394.- Cohecho pasivo impropio; Artículo 395.- Cohecho pasivo específico; Artículo 396.- Corrupción pasiva de auxiliares jurisdiccionales; Artículo 397.- Cohecho activo genérico; Artículo 397- A.Cohecho activo transnacional; Artículo 398.- Cohecho activo específico; Artículo 399.Negociación incompatible o aprovechamiento indebido de cargo; Artículo 400.- Tráfico de influencias; y, el Artículo 401.- Enriquecimiento ilícito.

En el numeral 1.3 se establece una penalidad a la empresa corrupta, perdiendo todo derecho resarcitorio o reclamo de devolución de inversión alguna que ya hubiere realizado en el proyecto en el marco del contrato, por ser la parte infractora.

En el numeral 1.4 se plantea la creación de una nueva garantía, la que llamaremos Garantía Anticorrupción, la que deberá emitirse y entregarse a la firma del contrato, conjuntamente con la garantía de fiel cumplimiento. La diferencia entre una y otra, es que la de fiel cumplimiento garantiza todas las demás obligaciones contractuales, entre tanto la cláusula anticorrupción solo se ejecuta ante la existencia o declaración de un acto de corrupción; es decir, el incumplimiento específico relacionado a la corrupción. 


\section{CONCLUSIONES}

- A nivel Internacional se tiene un marco legal supranacional que exhorta a los países a adecuar en sus legislaciones internas y a que desarrollen códigos y protocolos de ética que permitan prevenir, detectar y castigar los actos de corrupción de las empresas y del propio Estado. Entre ellos: "La Convención de las Naciones Unidas contra la Corrupción” (CNUCC), el Pacto Mundial de las Naciones Unidas. - "A Guide for Anti-Corruption Risk Assesment" y "El Convenio de lucha contra la corrupción de la Organización para la Cooperación y el Desarrollo Económicos" (OCDE), a través de la "La Guía de Buenas Prácticas sobre Control Interno, Ética y Cumplimiento de Normas".

- El BID y su estrategia "Fortalecimiento de un Marco Sistémico contra la Corrupción para el Banco Interamericano del Desarrollo" enfoca su política anticorrupción a través de tres (03) frentes: 1) fortalecer la integridad del personal del Banco; 2) que el financiamiento de sus proyectos, estén libres de corrupción; y, 3) otorgar préstamos a los países para fortalecer sus políticas públicas contra la corrupción.

- El Banco Mundial (BM) con su Guía Práctica contenida en el "Programa anticorrupción de ética y cumplimiento para las empresas", incluye como herramienta eficaz, la Evaluación de Riesgos de la Empresa.

- Transparencia Internacional (TI) publicó el Índice de Percepción de Corrupción a nivel mundial 2016, posicionándose el Perú en el puesto 101 de 167 países, con una puntuación de 35, conjuntamente con Gabón, Nigeria, Filipinas, Tailandia y Trinidad y Tobago.

- A nivel de normativa peruana, a partir del 7 de enero de 2017 existe la incorporación obligatoria del texto de la Cláusula Anticorrupción en los contratos de Obras Públicas recogidas en la Ley de Contrataciones del Estado y su reglamento, bajo sanción de nulidad.

- Entre los cambios normativos recientemente aprobados se establece la muerte civil para los funcionarios y servidores públicos corruptos por delitos contra la 
Administración Pública, la creación del Registro Único de Condenados Inhabilitados y el sistema de recompensas para funcionarios y ciudadanos. SINAD para denunciar actos de corrupción.

- La reciente emisión de medidas urgentes, vía el Decreto de Urgencia N. ${ }^{\circ} 003-$ 2017 para asegurar la continuidad de Proyectos de Inversión para la prestación de servicios públicos y cautelar el pago de la reparación civil a favor del Estado en casos de corrupción, parece que no ha cumplido su finalidad.

- La incorporación a nivel reglamentario en la normativa de Asociaciones Público Privadas (APP) de una cláusula anticorrupción, bajo responsabilidad parece obedecer más a un gesto político que a una medida eficaz o disuasiva.

- El Perú normativamente a nivel APP es un referente regional e internacionalmente importante, pero no es suficiente, en tanto se requiere estructurar un sistema integral a nivel Estado y empresariado que incentive las conductas correctas o llamadas "Buenas Prácticas" y que sancione ejemplarmente, las conductas ilegales o corruptas.

En tanto se deje un vacío legal a nivel normativo para interpretación o aplicación de la discrecionalidad del funcionario público, se abre la puerta a la corrupción. Por ello, implementar la cláusula anticorrupción en todos los contratos de inversión del Estado es importante pero no suficiente. Existen otros mecanismos que complementarán la referida cláusula y que permitirán blindar el sistema de APP, entre ellos: la prohibición de renegociar condiciones de competencia, la posibilidad de suscribir adendas sólo dentro de los tres primeros años y en tres únicos supuestos.

- El Estado peruano tiene las herramientas legales y los lineamientos establecidos para evaluar si el proyecto debe conducirse como APP o debe ir como obra pública, siendo el más importante el criterio "Valor por dinero", que, si bien está recogido normativamente, en la práctica, no se viene aplicando.

- La Ley de Contrataciones del Estado y su reglamento han liderado la reforma contra la corrupción a nivel contractual, estableciendo, bajo sanción de nulidad, la obligatoriedad de incorporar taxativa y textualmente, la cláusula anticorrupción al desarrollar íntegramente el contenido de la misma en el reglamento. 
- La normativa de APP sólo ha recogido a nivel reglamentario, la obligatoriedad de incorporar, bajo sanción de nulidad, una cláusula anticorrupción. Dejando así, a discreción de los funcionarios públicos sectoriales o de Proinversión y/o del MEF, el contenido y redacción de la misma.

- La no estandarización de las cláusulas contractuales en los proyectos de inversión en los que participa el Estado, en particular, la cláusula anticorrupción, genera distorsiones en su constitución, interpretación, y, en consecuencia, en su ejecución y aplicación.

- Establecer una cláusula anticorrupción a raja tabla que obligue al Estado a resolver automáticamente el contrato, ante la comisión o declaración de comisión de un acto de corrupción sea en el Perú o en el extranjero, produce que los efectos de su aplicación, pueda a su vez generar en algunos casos, un mayor perjuicio a la población y al Estado, porque se resolvería el contrato y paralizaría el proyecto.

- De presentarse o declararse un acto de corrupción de una empresa en el Perú, la resolución del contrato, debe establecerse como alternativa potestativa del Estado peruano, según el nivel de corrupción presentado, debiendo establecer legal y contractualmente dichos niveles en la cláusula anticorrupción y los casos en el que procede la cesión de posición contractual que permitirá la permanencia del contrato y la continuidad del proyecto de inversión.

- La propuesta de cláusula de anticorrupción establece un procedimiento entre las partes de presentarse indicios, potenciales actos u actos de corrupción menores, que permita comunicar a la otra parte, del hecho o indicio y de las acciones inmediatas correctivas tomadas y en todo caso, las sanciones establecidas.

- La propuesta de cláusula anticorrupción propone un modelo mixto, facultativo del Estado para activarla por la resolución del contrato en caso se trate de un acto de corrupción de cierto nivel ó cuando se opte por la cesión de posición contractual que permita la continuidad del proyecto.

- La propuesta recoge incorporar una garantía adicional a la de fiel cumplimiento que deberá suscribir la empresa y es, la "Garantía Anticorrupción", debiendo emitirse una carta fianza equivalente al $4 \%$ del valor total del Contrato. 
- La Política Anticorrupción de un país para que sea efectiva, debe estar traducida en un Programa Anticorrupción que contemple buenas prácticas anticorrupción, entre ellas, la evaluación de los riesgos de corrupción, la detección de los actos de corrupción y la imposición de sanciones públicamente.

- Una Política Anticorrupción eficiente y efectiva solo es posible con un "Análisis de Riesgos", es decir, con una evaluación profesional sobre la identificación, priorización, calificación y mitigación de riesgos realizados por las empresas y por el propio Estado a través de sus organizaciones. Principalmente, que incluya una matriz de riesgos anticorrupción y acciones preventivas, correctivas y sancionadoras.

- La Cláusula Anticorrupción en los contratos de Inversión en Infraestructura, desde una perspectiva legal, es un mecanismo disuasivo para la empresa inversionista y que debe ser vista como una medida drástica por parte del Estado a través de la resolución del contrato que pone fin al proyecto, pero, desde una perspectiva económica, puede convertirse, con la sola sospecha -de posible corrupción-, en un arma draconiana convirtiéndose, en impedimento de bancabilidad del proyecto, que termina finalmente, con el mismo efecto: resolviéndose el contrato y en consecuencia el proyecto. 


\section{RECOMENDACIONES}

El presente trabajo de investigación ha permitido evaluar y establecer la problemática de la normativa de la APP, de la cláusula anticorrupción y del sistema integral de la APP, lo que, a su vez, frente a esas falencias, nos permitimos recomendar ciertas medidas:

- Aprobar un Plan Estratégico Nacional de Priorización de Proyectos de Inversión en Infraestructura a nivel país, con base a un Plan Multianual de Infraestructura de cada sector. El procedimiento en la elaboración, sustentación y aprobación del referido Plan Estratégico debiera darse en audiencias públicas y pre publicarse.

- Normativamente se recomienda re definir claramente los roles y funciones de cada uno de los actores de la APP, es decir, qué temas y documentos les corresponde evaluar, opinar y aprobar a cada uno: Ministerio de Economía y Finanzas (MEF), Proinversión, Contraloría General de la República, Reguladoras de los Sectores, Ministerios, Gobiernos Regionales y Locales, etc.

- Se recomienda estandarizar normativamente, todas las cláusulas de los contratos de inversión en infraestructura, incorporando en ese sentido, una cláusula anticorrupción estándar en todos ellos, que incorpore una fórmula mixta que permita facultativamente al Estado, ante determinados supuestos específicos graves de corrupción, aplicar la nulidad del contrato y en el resto de supuestos, la cesión de posición contractual con carta fianza anticorrupción por la cual la empresa entrante sólo responderá por los actos de corrupción desde su ingreso al contrato en adelante, así se conservará el contrato, sin afectar el proyecto.

- El despliegue normativo y de avanzada para evitar o mitigar los actos de corrupción en particular en la normativa APP, es relevante, pero es insuficiente, pues debe ir acompañado del fortalecimiento de capacidades de los servidores públicos y en consecuencia del fortalecimiento de las instituciones públicas, brindándoles herramientas que permitan eliminar la discrecionalidad, que es finalmente, un foco atrayente de la corrupción. 
- Obtener por parte de las empresas postoras, un puntaje adicional en las convocatorias u otros incentivos, para aquellas que cuenten con las Certificación ISO 37001. - Sistema de Gestión Antisobornos. Para las entidades públicas debiera ser obligatorio en un plazo determinado que obtengan la referida certificación en todos sus sistemas y procedimientos. 


\section{REFERENCIAS}

Banco Interamericano de Desarrollo. (2017). Temas Transparencia. Transparencia, responsabilidad y anticorrupción. Recuperado de http://www.iadb.org/es/temas/transparencia/transparencia-yanticorrupcion, $1162 . \mathrm{html}$

Banco Interamericano de Desarrollo. (2009). Políticas y Estrategias [Versión PDF]. Recuperado de http://www.iadb.org/es/temas/transparencia/apoyo-a-lospaises/politicas-y-estrategias, 1179.html

Banco Interamericano de Desarrollo. (2009). Plan de Acción para el Apoyo a los Países en sus Esfuerzos por Combatir la Corrupción y Fomentar la Transparencia [Versión PDF]. Recuperado de http://www.iadb.org/es/temas/transparencia/apoyo-a-lospaises/paact,6741.html

Banco Interamericano de Desarrollo. (2001). Strengthening a systemic framework against corruption for the Inter-america Development Bank [Versión PDF]. Recuperado de http://idbdocs.iadb.org/wsdocs/getdocument.aspx?docnum=815064

Banco Interamericano de Desarrollo. Perú Grupo Andino CAN. Recuperado de http://www.iadb.org/es/paises/peru/peru-y-el-bid,1037.html

Banco Mundial. Normas: Selección y Contratación de Consultores. Con Préstamos del BIRF, Créditos de la AIF y Donaciones por Prestatarios del Banco Mundial [Versión PDF]. Recuperado de http://siteresources.worldbank.org/INTPROCUREMENT/Resources/2780191308067833011/Consultant_GLs_Spanish_Final_Jan2011.pdf

Banco Mundial. Perú Proyectos y Programas. Recuperado de http://www.bancomundial.org/es/country/peru/projects

Centro de Desarrollo Industrial (CDI). Sociedad Nacional de Industrias. (29 de setiembre de 2015). Nota de Prensa WEF Publica Informe de Competitividad Global 2015-2016. Recuperado de http://www2.congreso.gob.pe/sicr/cendocbib/con4_uibd.nsf/E54FA8181F9A9 4B005257ED50065D64A/\$FILE/NOTA_DE_PRENSA_IGC_20152016_CDI.pdf

Contraloría General de la República. Denuncia la Corrupción del Sistema Nacional de Atención de Denuncias (SINAD). Recuperado de ttps://appscgr.contraloria.gob.pe/sinad

Decreto de Urgencia N. ${ }^{\circ}$ 003-2017, Decreto de Urgencia que asegura la continuidad de Proyectos de Inversión para la prestación de Servicios Públicos y cautela el 
pago de la reparación civil a favor del Estado en casos de corrupción. (13 de febrero de 2017). Recuperado del sitio de internet del Congreso de la República del Perú http://www.leyes.congreso.gob.pe/Documentos/DecretosDeUrgencia/2017003 .pdf

Decreto Legislativo N. ${ }^{\circ}$ 1341, Decreto Legislativo que modifica la Ley 30225, Ley de Contrataciones del Estado. (7 de enero de 2017). Recuperado del sitio de internet del Congreso de la República del Perú http://www.leyes.congreso.gob.pe/Documentos/DecretosLegislativos/01341.p df

Decreto Legislativo N. ${ }^{\circ}$ 1251, Decreto Legislativo que Modifica el Decreto Legislativo N ${ }^{\circ} 1224$, Ley Marco de Promoción de la Inversión Privada mediante Asociaciones Público Privadas y Proyectos en Activos. (30 de noviembre de 2016). Recuperado del sitio de internet del Congreso de la República del Perú http://www.leyes.congreso.gob.pe/Documentos/DecretosLegislativos/01251.p df

Decreto Legislativo N. ${ }^{\circ}$ 1243, Decreto Legislativo que modifica el Código Penal y el Código de Ejecución Penal a fin de establecer y ampliar el Plazo de duración de la Pena de Inhabilitación Principal e Incorporar la Inhabilitación Perpetua para los Delitos cometidos contra la Administración Pública, y crea el Registro Único de Condenados Inhabilitado. (22 de octubre de 2016). Recuperado del sitio de internet del Congreso de la República del Perú http://www.leyes.congreso.gob.pe/Documentos/DecretosLegislativos/01243.p df

Decreto Legislativo N. ${ }^{\circ}$ 1234, Decreto Legislativo que modifica el Código Penal y el Código de Ejecución Penal a fin de establecer y ampliar el plazo de duración de la pena de inhabilitación principal, e incorporar la inhabilitación perpetua para los delitos cometidos contra la administración pública, y crea el registro único de condenados inhabilitados. (26 de setiembre de 2015). Recuperado del sitio de internet del Congreso de la República del Perú http://www.leyes.congreso.gob.pe/Documentos/DecretosLegislativos/01234.p df

Decreto Legislativo N. ${ }^{\circ}$ 1224, Decreto Legislativo del Marco de Promoción de la Inversión Privada mediante Asociaciones Público Privadas y Proyectos en Activos. (25 de setiembre de 2015). Recuperado del sitio de internet del Congreso de la República del Perú http://www.leyes.congreso.gob.pe/Documentos/DecretosLegislativos/01224.p df

Decreto Legislativo N. ${ }^{\circ}$ 1017, Ley de Contrataciones del Estado. (4 de junio de 2008). Recuperado del sitio de internet del Congreso de la República del Perú http://www.leyes.congreso.gob.pe/Documentos/DecretosLegislativos/01017.p df 
Decreto Legislativo N. ${ }^{\circ}$ 1012, Ley Marco de Asociaciones Público - Privadas para la Generación de Empleo Productivo y dicta Normas para la Agilización de los Procesos de Promoción de la Inversión Privada (13 de mayo de 2008). Recuperado del sitio de internet del Congreso de la República del Perú http://www.leyes.congreso.gob.pe/Documentos/DecretosLegislativos/01012.p df

Decreto Legislativo N. ${ }^{\circ}$ 635, Código Penal. (8 de abril de 1991). Recuperado del sitio de internet del Congreso de la República del Perú http://www.leyes.congreso.gob.pe/Documentos/DecretosLegislativos/00635.p df

Decreto Legislativo N. ${ }^{\circ}$ 295, Código Civil. (25 de julio de 1984). Recuperado del sitio de internet del Congreso de la República del Perú. Recuperado del sitio de internet del Congreso de la República del Perú http://www.leyes.congreso.gob.pe/Documentos/DecretosLegislativos/00295.p df

Decreto Supremo N. ${ }^{\circ}$ 068-2017-EF, Decreto Supremo que modifica el Decreto Supremo No 410-2015-EF, Reglamento del Decreto Legislativo $N^{\circ} 1224$, Ley Marco de Promoción de la Inversión Privada mediante Asociaciones Público Privadas y Proyectos en Activos. (28 de marzo de 2017). Recuperado del sitio de internet del Ministerio de Economía y Finanzas https://www.mef.gob.pe/es/por-instrumento/decreto-supremo/15736-decretosupremo-n-068-2017-ef/file

Decreto Supremo N. ${ }^{\circ}$ 056-2017-EF, Decreto Supremo que modifica el Reglamento de la Ley $\mathrm{N}^{\circ} 30225$, Ley de Contrataciones del Estado, aprobado por el Decreto Supremo N. ${ }^{\circ} 350-2015-E F$. (19 de marzo de 2017). Recuperado del sitio de internet del Ministerio de Economía y Finanzas https://www.mef.gob.pe/en/por-instrumento/decreto-supremo/15697-decretosupremo-n-056-2017-ef/file

Decreto Supremo N. ${ }^{\circ}$ 184-2008-EF, Reglamento del Decreto Legislativo N ${ }^{\circ} 1017$ que aprobó la Ley de Contrataciones del Estado. (19 de julio de 2008). Recuperado del sitio de internet del Ministerio de Economía y Finanzas https://mef.gob.pe/es/normativa-sp-28036/5898-d-s-n-184-2008-ef-1/file

De la Puente y Lavalle, Manuel. El contrato en general. Comentarios a la Sección Primera del Libro VII del Código Civil. Tomo II, Título VI. Contrato con prestaciones recíprocas, Artículo 1430. Recuperado de https://vlex.com.pe/vid/articulo378245862?_ga=2.23061757.772235623.1497210584408732095.1497121862

Economist Intelligence Unit. (2010). Evaluando el entorno para las asociaciones público-privadas en América Latina y el Caribe. Guía de Índice y Metodología. Recuperado de https://publications.iadb.org/bitstream/handle/11319/6172/Evaluando\%20el\% 20entorno\%20para\%20las\%20asociaciones\%20público- 
privadas $\% 20$ en $\% 20$ América\%20Latina\%20y\%20el\%20Caribe.\%20Infrascope $\% 202010 \% 20$.pdf? sequence $=1 \&$ is Allowed $=\mathrm{y}$

Ejecutivo oficializó ley de muerte civil para corruptos. (22 de octubre de 2016). El Comercio. Recuperado de http://elcomercio.pe/politica/gobierno/ejecutivooficializo-ley-muerte-civil-corruptos-273517

Expansión / Datosmacro.com. Perú - Índice de Percepción de la Corrupción. Recuperado de http://www.datosmacro.com/estado/indice-percepcioncorrupcion/peru

Herrera Velarde, Eduardo. (2016). La famosa cláusula anticorrupción [Versión PDF]. Recuperado de http://www.lucidez.pe/opinion/la-famosa-cláusulaanticorrupcion-por-eduardo-herrera/

Índice de Percepción de la Corrupción 2016 de Transparency International.s.f.. Recuperado de http://transparencia.org.es/wpcontent/uploads/2017/01/tabla_sintetica_ipc-2016.pdf

Lazo, Magali. (8 de setiembre de 2016). Nuevas reglas de fomento de la inversión privada mediante APP. Revista Legal N. ${ }^{\circ} 189$. Estudio Muñiz, Ramírez Pérez -Taíman \& Olaya, Abogados [Versión PDF]. Recuperado de http://esmuniz.tumblr.com/post/150122930311/nuevas-reglas-de-fomento-ala-inversi\%C3\%B3n

Ley N. ${ }^{\circ}$ 30225, Ley de Contrataciones del Estado. (11 de julio de 2014). Recuperado del sitio de internet del Congreso de la República del Perú http://www.leyes.congreso.gob.pe/Documentos/Leyes/30225.pdf

Ministerio de Economía y Finanzas del Perú. (2017). Las Asociaciones Publico Privadas [Versión PDF]. Recuperado de https://www.mef.gob.pe/es/obraspor-impuestos?id=3971

Oficina de las Naciones Unidas contra la Droga y el Delito. (2013). Programa anticorrupción de ética y cumplimiento para las empresas: Guía práctica [Versión PDF]. Recuperado de https://www.unodc.org/documents/corruption/Publications/2013/1385255_Ebook.pdf

Paralización de obras de Odebrecht deja sin empleo a 15,000 obreros, advierte Construcción Civil. (28 de enero de 2017). Gestión. Recuperado de http://gestion.pe/empleo-management/paralizacion-obras-odebrecht-deja-sinempleo-15000-obreros-advierte-construccion-civil-2180802

PPK prefiere volver a licitar en nueve meses el Gasoducto Sur Peruano. (26 de enero de 2017). Gestión. Recuperado de http://gestion.pe/economia/ppk-prefierevolver-licitar-nueve-meses-gasoducto-sur-peruano-2180666

PROINVERSION. Contrato de Concesión. Carretera Longitudinal de la Sierra, Tramo 4.Huancayo-Izcuchaca-Mayocc-Ayacucho/Ayacucho-AndahuaylasPuente-Sahuinto/Dv. Pisco - Huaytará - Ayacucho. (Versión Final) [Versión PDF]. (24 de junio de 2015). Recuperado de 
http://www.proyectosapp.pe/RepositorioAPS/0/2/JER/ST_LONG_TRAMO4/ Version_Final_Contrato_al_24_06_2015.pdf, p.94-96.

PROINVERSION. Contrato de Concesión. Mejoras a la Seguridad Energética del País y Desarrollo del Gaseoducto Sur Peruano (Versión Final) [Versión PDF]. (Mayo de 2014). Recuperado de http://www.proyectosapp.pe/RepositorioAPS/0/2/JER/PC_H_SEGURIDAD/ VF_APROBADA_POR_CD.pdf, p.36 y 97.

Ranking Latinoamérica y el Caribe - IGC 2015-2016. (25 de setiembre de 2015). CDI-SIN. Recuperado de http://www2.congreso.gob.pe/sicr/cendocbib/con4_uibd.nsf/E54FA8181F9A9 4B005257ED50065D64A/\$FILE/NOTA_DE_PRENSA_IGC_20152016_CDI.pdf

Ronceros, Miguel Angel. (24 de enero de 2017). Contratos y cláusulas anticorrupción. El Comercio. Recuperado de https://www.google.com.pe/amp/elcomercio.pe/amp/opinion/colaboradores/co ntratos-y-cláusulas-anticorrupcion-miguel-angel-ronceros-noticia-1962861

SEMANA Economica.com. (9 de setiembre de 2014). CAF: Cartera de créditos al Perú en el 2014 ascendería a US\$2,400 millones. Recuperado de http://semanaeconomica.com/article/infraestructura/143617-caf-cartera-decreditos-al-peru-en-el-2014-ascenderia-a-us2400-millones/

Sin tregua contra la corrupción. (10 de junio de 2017). El Peruano. Recuperado de http://www.elperuano.com.pe/noticia-sin-tregua-contra-corrupcion51119.aspx

Superintendencia del Mercado de Valores - SMV. (2015). Reglamento de Propiedad Indirecta, Vinculación, y Grupos Económicos (RSMV N. ${ }^{\circ}$ 019-2015SMV/01). [Versión PDF]. Recuperado de http://www.smv.gob.pe/sil/RSMV00001500019002.pdf

The Economist Intelligence Unit Limited 2017 (2017). Recuperado de http://infrascope.eiu.com/wpcontent/uploads/2017/02/EIU_IDB_INFRASCOPE_2017-FINAL-1.pdf

The Global Competitiveness Report 2016-2017. p. xiii. Recuperado de http://www.cdi.org.pe/pdf/IGC/20162017/the_global_competitiveness_report_2016-2017.pdf

Word Economic Forum (WEF) o Fórum Económico Mundial. (2016). Informe de Competitividad Global 2016-2017. Recuperado de http://www3.weforum.org/docs/GCR20162017/05FullReport/TheGlobalCompetitivenessReport2016-2017_FINAL.pdf. 


\section{BIBLIOGRAFÍA}

Alborta, Guillermo R.; Stevenson, Claudia; Triana, Sergio. (2011). Asociaciones público privadas para la prestación de servicios Una visión hacia el futuro. Banco Interamericano de Desarrollo (BID). Recuperado de https://publications.iadb.org/handle/11319/5062

Devlin R. y Moguillansky G. (2010). Alianzas público-privadas para una nueva visión estratégica del desarrollo. Secretaria General Iberoamericana. CEPAL, Naciones Unidas. Recuperado de http://repositorio.cepal.org/bitstream/handle/11362/2562/1/S0900893_es.pdf

Programa de la subasignatura: cláusula anticorrupción de la Cámara de Comercio internacional (CCI) Introducción a la Cámara de Comercio internacional: Recuperado de http://www.reingex.com/Cláusula-Anticorrupcion-ICC.shtml

Wolf, Nick y Sanchez, Vanesa (2013). Infrascope 2012: Evaluando el entorno para las asociaciones público-privadas en América Latina y el Caribe. Banco Interamericano de Desarrollo (BID). Recuperado de https://publications.iadb.org/handle/11319/5839

Rebollo, A. (2009). Experiencia española en concesiones y asociaciones públicoprivadas para el desarrollo de infraestructuras públicas: Marco general. Banco Interamericano de Desarrollo (BID). Recuperado de https://publications.iadb.org/handle/11319/6174

Rebollo, A. (2010). Las asociaciones público-privadas (APP): una opción para contratación administrativa en Latinoamérica. Foro Revista de Derecho, N. ${ }^{\circ}$ 13, Universidad Andina Simón Bolívar Sede Ecuador. Corporación Editorial Nacional, Quito, Ecuador. Recuperado de http://revistas.uasb.edu.ec/index.php/foro/article/view/383/379

Pliscoff, C. y Araya J.P. (2012). Las alianzas público-privadas como gatilladoras de innovación en las organizaciones públicas: reflexiones a partir de la situación chilena. Estado, Gobierno, Gestión Pública. Revista Chilena de Administración Pública. ISSN 0717-6759 Nº19. Recuperado de http://repositorio.uchile.cl/bitstream/handle/2250/123487/las-alianzaspublico-privadas-como-gatilladoras-de-innovacion-en-las-organizacionespublicas.pdf; sequence $=1$ 


\section{ANEXOS}




\section{ANEXO 1: ENTREVISTAS A ESPECIALISTAS EN APP}

1.- Cuestionario de preguntas al especialista de APP, Ingeniero René Cornejo Díaz efectuada en mayo del 2017.

Presidente del Consejo de Ministros del Perú (febrero - julio 2014). Ministro de Vivienda Construcción y Saneamiento- (julio 2011 - febrero 2014). Director Ejecutivo de PROINVERSION (2004 -2007).

2.- Entrevista personal al especialista de APP, Economista Alonso Segura Vasi efectuada en mayo del 2017.

Ministro de Economía y Finanzas del Perú (MEF) (setiembre 2014 - julio 2016) y en dicha calidad, Presidente de PROINVERSION. Jefe de Gabinete del Ministerio de Economía y Finanzas del Perú (MEF) y Jefe del destrabe en los proyectos de APP del MEF. Presidente del Comité de Proyectos de Inversión Pública de PROINVERSION. En el FMI fue asesor de gobiernos en temas de APP.

\section{Cuestionario de Entrevista}

La problemática de las APPs en el Perú con ocasión de la Cláusula Anticorrupción.

1) ¿Qué acercamiento y experiencia ha tenido Ud. con las APPs en el Perú?

2) ¿Qué acercamiento y/o experiencia ha tenido Ud. con las APPs a nivel Internacional?

3) En base a esa experiencia que ha observado tanto a nivel normativo y a nivel de gestión, ¿qué buenas prácticas de otros países debiera recogerse y/o aplicarse en el Perú?

4) En su experiencia, la posibilidad de Renégociar los contratos y suscribir adendas, le abre las puertas a la corrupción?, es decir, limitando esta posibilidad como lo ha recogido el reglamento de la Ley de APPs, será una herramienta efectiva que reducirá o evitará la corrupción?

5) ¿Son las APPs un sistema eficiente en el Perú? Si, No, ¿Por qué? 
6) ¿En qué casos el Estado debe apostar por una APP y no por el sistema de obras públicas. Cual (es) criterio (s) debiera (n) ser determinante (s) para tomar tal decisión? ¿Se aplica(n) dicho (s) criterio (s) en la práctica?

7) ¿Podría darnos una definición de Cláusula Anticorrupción?

8) ¿Para qué sirve una cláusula Anticorrupción en un contrato de Inversión con el Estado? Qué herramientas tenía el Estado Peruano antes de ser recogida en un contrato de inversión?

9) ¿Qué precisiones debe contener una cláusula anticorrupción para que sea efectiva y no se quede en el papel?

10) ¿Es suficiente una Cláusula Anticorrupción?. ¿Qué otras medidas o acciones se necesitaría implementar para evitar los casos de corrupción en el marco de las APPs si es que se da por una falta de legislación adecuada o hay otros factores que influyen?

11) Otras preguntas o posiciones sobre el tema que Ud. considere relevante. 